\title{
Emergency contraception in Zambia: Setting a new agenda for research and action
}

Yusuf Ahmed

M. Ketata

John P. Skibiak

Population Council

Follow this and additional works at: https://knowledgecommons.popcouncil.org/departments_sbsr-rh

Part of the Demography, Population, and Ecology Commons, International Public Health Commons, Maternal and Child Health Commons, and the Women's Health Commons How does access to this work benefit you? Let us know!

\section{Recommended Citation}

Ahmed, Yusuf, M. Ketata, and John P. Skibiak. 1998. "Emergency contraception in Zambia: Setting a new agenda for research and action." Nairobi: Population Council. 


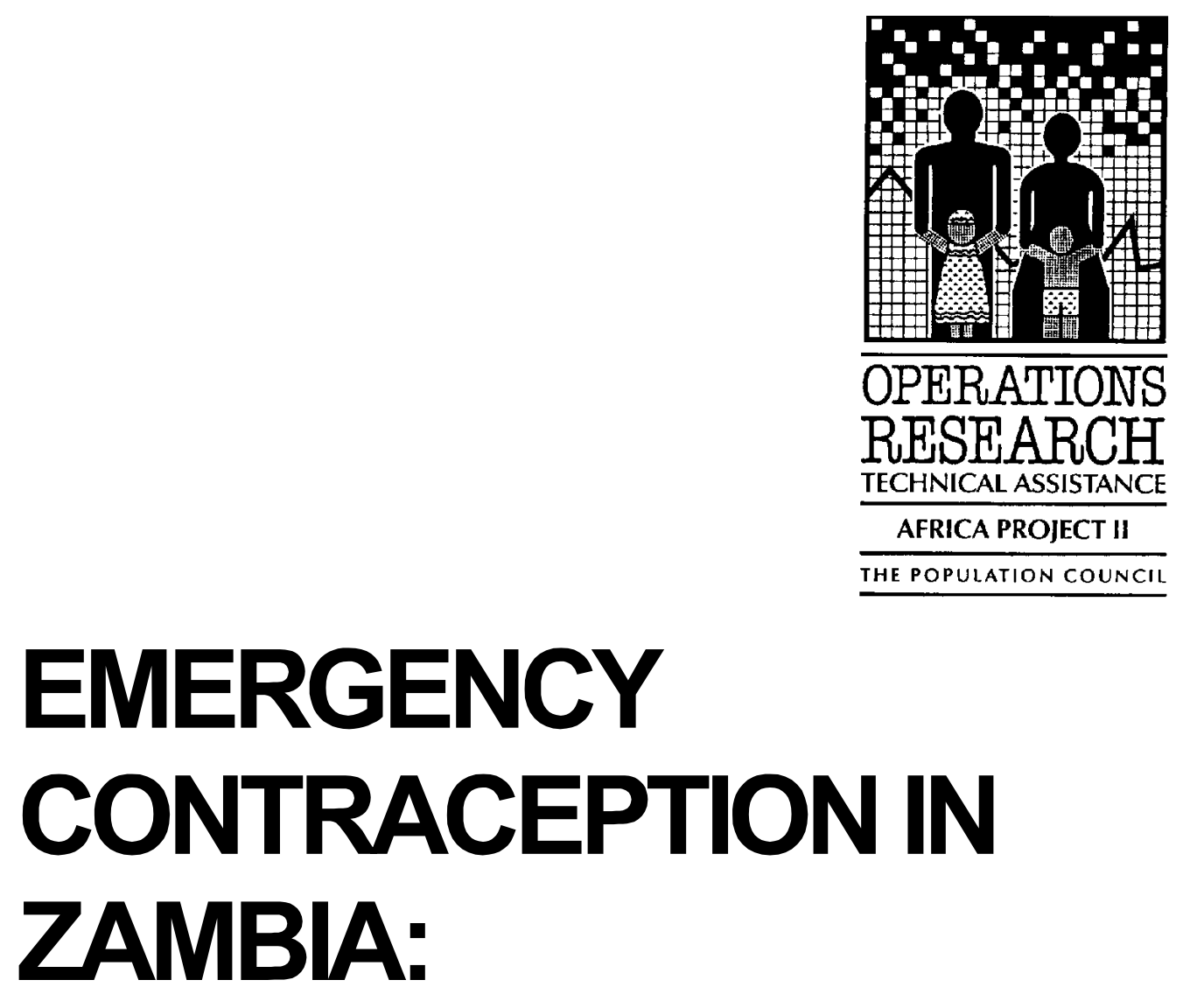

SETTING A NEW AGENDA FOR RESEARCH AND ACTION

Y Ahmed, University Teaching Hospital M Ketata, University Teaching Hospital J P Skibiak, Population Council 


\section{The Population Council}

The Population Council seeks to help improve the well-being and reproductive health of current and future generations around the world and to help achieve a humane, equitable, and sustainable balance between people and resources. The Council analyzes population issues and trends; conducts biomedical research to develop new contraceptives; works with public and private agencies to improve the quality and outreach of family planning and reproductive health services; helps governments to influence demographic behavior; communicates the results of research in the population field to appropriate audiences; and helps build research capacities in developing countries. The Council, a nonprofit, nongovernmental research organization established in 1952, has a multinational Board of Trustees; its New York headquarters supports a global network of regional and country offices.

\section{Africa OR/TA Project II}

The overall objective of the Africa OR/TA Project II is to broaden understanding of how to improve family planning services in Sub-Saharan Africa, and to apply operations research and technical assistance to improve services by:

- increasing access to a full range of family planning services and methods;

- developing service delivery strategies that are client-oriented and acceptable to various population groups;

- improving the operations of programs to make them more efficient and financially sustainable;

- improving the quality of services;

- strengthening the capabilities of family planning program managers to use operations research to diagnose and solve service delivery problems.

Publication of this document was made possible with support from the Population Council's Operations Research and Technical Assistance Project II, Project No. 936-3030. 


\section{TABLE OF CONTENTS}

ACKNOWLEDGEMENTS

INTRODUCTION

BACKGROUND 2

PROJECT OUTPUTS AND DATA COLLECTION ACTIVITIES 4

PROVIDER TRAINING

DELIVERY OF EMERGENCY CONTRACEPTION

DATA COLLECTION 6

Survey among Termination of Pregnancy Clients 6

MCH/FP Client Survey $\quad 6$

Provider Interviews 6

Focus Group Discussions among University Students $\quad 7$

$\begin{array}{ll}\text { Client History Forms } & 7\end{array}$

RESEARCH FINDINGS AND PROGRAMMATIC IMPLICATIONS 8

ACCESSIBILITY $\quad 9$

Do age or civil status influence access?

Is prior knowledge about emergency contraception necessary? 11

Are accessible services and information enough? 13

Do attitudes and interests of women vary? 13

$\begin{array}{ll}\text { ADMINISTRATION } & 17\end{array}$

Do barriers exist that hinder timely access? 17

FOLLOW-UP AND MANAGEMENT OF SIDE EFFECTS 19

Is routine client follow-up necessary? 19

What constraints hinder follow-up? 21

$\begin{array}{ll}\text { TRAINING } & 24\end{array}$

Are training strategies for traditional family planning also appropriate for emergency contraception? 24

Why is broad method choice so important? $\quad 25$

TRANSITION TO REGULAR FAMILY PLANNING 27

Is the relationship between regular family planning

Does emergency contraception encourage adoption of more effective contraceptive methods? 28

What is the role of emergency contraception for

SUMMARY OF PROGRAMMATIC IMPLICATIONS 31

$\begin{array}{ll}\text { DISSEMINATION WORKSHOP } & 33\end{array}$

$\begin{array}{ll}\text { REFERENCES } & 37\end{array}$ 


\section{ACKNOWLEDGEMENTS}

The authors would like to express their gratitude to those people whose collaboration and support have made it possible to achieve, in so short a period of time, the project activities and findings described in this report.

Special thanks goes to Dr. Davy Chikamata of the Population Council's Program for Expanding Contraceptive Choice who, from the outset, has played a critical role in helping to conceptualize the original study design, in training service delivery providers, and in delineating a strategic framework for the introduction of contraceptive technologies. Many thanks are also due to Mr. Peter Hall of WHO/HRP whose commitment and ongoing support to this project have not only ensured the timely implementation of critical research activities, but also made possible WHO's sponsorship of a national workshop to disseminate the results described in this report. Finally, the authors wish to thank Mr. Paul Hartenberger of USAID/Zambia for his confidence in the ability of UTH and the Population Council to undertake what still stands as one of the few operations research studies on emergency contraception in a developing country context.

One of the truly distinctive features of this study is the fact that it has been, ever since its inception, a highly participatory exercise. Most of the project's service delivery, training and even data collection components are managed by a steering committee whose membership is drawn from providers at each of the service delivery points involved in the project. The authors would like to convey their gratitude to all of these providers and, of course, to their respective institutions:

$\begin{array}{lc}\text { Consilia Miyutu, Chawama Clinic } & \text { Zenobia Ng’ombe, PPAZ } \\ \text { Esther Kabombo, Chawama Clinic } & \text { Catherine Makai, PPAZ } \\ \text { Queen Lwesha, Chipata Clinic } & \text { C. Mwenefumbo, PPAZ } \\ \text { Violet Lungu, Chipata Clinic } & \text { M. Wina, PPAZ } \\ \text { Monica Tembo, Chipata Clinic } & \text { Laura Mafuta, UNZA } \\ \text { Christina Matibini, Mtendere Clinic } & \text { Godfrida Changala, UTH CO3 } \\ \text { Billies Imakando. Mtendere Clinic } & \text { Charity Mwango, UTH CO3 } \\ \text { Siyapuku Chabbela, Mtendere Clinic } & \end{array}$

And lastly, the authors would be remiss if credit were not give to a number of individuals who, often without warning, were called upon to help out at critical moments in the project's implementation. To these individuals: Dr. Jantine Jacobi (WHO), Ms. Tamara Fetters (CARE), Dr. Kathleen Siachitema (Population Council) and Ms. Moonga Simuyandi (UTH) we offer our many thanks.

Of course, none of the activities described in this report would have been possible without the generous support of the project's funding agencies. For that support, we wish to thank the United States Agency for International Development, the World Health Organization, the Canadian Public Health Association, and the British Department for International Development. 


\section{INTRODUCTION}

This report summarizes the activities and findings of the first phase of the operations research study, Enhancing Access to Family Planning Services through the Introduction of Emergency Contraception. Launched in September 1997, the study is designed to explore a broad range of issues relating to emergency contraception within a developing country context. With financial and technical support from the United States Agency for International Development, the World Health Organization, the Canadian Public Health Association, and the British Department for International Development (DFID), the study consists of two phases: an initial exploratory exercise in which strategies are identified for overcoming difficulties associated with the introduction or delivery of emergency contraception services; and a subsequent research phase, in which individual operations research studies are developed to test the problem solving strategies identified previously.

The present report is divided into four major sections. The first recounts the events and circumstances leading to the development of this study, and it describes the roles of the various organizations participating in it. The second section follows with a summary of the outputs and principal data collection activities during Phase One. The third section details the research findings of Phase One and outlines their implications for future programmatic activities, including the design of subsequent operations research studies. Finally, the fourth section describes the results of a national workshop, held on March 10, 1998 to disseminate the results of Phase One data collection activities and to identify areas for future research and action. 


\section{BACKGROUND}

In 1995, a national assessment of contraceptive needs in Zambia (WHO, 1995) found that despite ongoing efforts to strengthen the delivery of family planning services, for many potential users, access to contraception remains severely limited. One of the major factors contributing to this is the persistence of cultural norms and provider biases that effectively withhold services from women who are either unmarried or who fail to secure the approval of a male partner. The same is also true for Zambian youth who, despite their risks of STI transmission and unplanned pregnancy, feel obliged to seek out alternative outlets for reproductive health services and information ${ }^{1}$.

Given the persistence and pervasive nature of such barriers, the 1995 assessment concluded that emergency contraception could very well play a critical role in limiting unwanted pregnancies, reducing the need for unsafe abortion, and, ultimately, in lowering rates of maternal mortality and morbidity ${ }^{2}$. To this end, it recommended adoption of the Yuzpe regimen involving provision of two high dose oral contraceptive tablets within 72 hours of intercourse followed by a further two tablets 12 hours later.

Though emergency contraception still remains largely unknown in most parts of Zambia, there is growing interest on the part of many providers to introduce this method into their ongoing service delivery programs. Fortunately, two recent events have now made it easier for them to do so. The first was the procurement by the Zambia Ministry of Health of combined oral contraceptives packaged exclusively for emergency contraception use (manufactured by the German pharmaceutical firm, Schering, under the brand name $P C-4)^{3}$. The second was the unveiling in June 1997 of Zambia's Policy Framework and Guidelines for Family Planning which, for the first time, identifies emergency contraception as a key component of the national family planning method mix (Zambia 1997).

Although interest in emergency contraception has grown dramatically in recent years, the introduction of this method entails uncertainties and questions for which the delivery of traditional family planning services -- especially in developing countries -- provides very few answers. One area of concern, for example, relates to the importance of enhancing accessibility, not only to the contraceptive product itself, but also to the information a user must have before she will seek out the product in the first place. Another broad area of concern has been product administration and dispensing, specifically, the implications on accessibility and efficacy of "prophylactic" distribution of emergency contraceptive pills; as well as the consequences of dispensing "dedicated" products rather than the cutting up of existing pill cycles. Still other issues of importance include the identification of appropriate strategies for managing side effects, for encouraging the transition from emergency contraception to routine use of family planning methods, and, finally, for the training of a

\footnotetext{
${ }^{1}$ According to the 1992 Zambia DHS, nearly one-third of all women below the age of 17 have either been pregnant or already had a first child; by age 19, this proportion jumps to two-thirds (Gaisie 1993: 35-36).

${ }^{2}$ A study carried out in Zambia's Western Province found that 12 percent of women aged 15-19 years had undergone a clandestine abortion. (Koster 1995: 15-18). Moreover, of the total number of recorded abortionrelated deaths since 1970, over half (56 percent) occurred among school girls.

${ }^{3}$ One packet of PC-4 contains four oral contraceptive tablets each containing levonorgestrel, $250 \mu \mathrm{g}$ plus ethinyl estradiol, $50 \mu \mathrm{g}$
} 
potentially wide range of service providers.

Unfortunately, most of what we know about these issues comes from the delivery of services in developed countries, where access to information and the communication media is greater, where contraceptive prevalence overall is higher, and where so large a percentage of potential users can be reached through formal institutional frameworks such as universities, youth centers, public health care facilities and the like.

For that reason, in September 1997, the University Teaching Hospital launched an operations research study to identify and then explore more closely the range of issues relating to emergency contraception within a developing country context. With financial and technical support from the Population Council ${ }^{4}$, the World Health Organization, the Canadian Public Health Association, and Britain's Department for International Development (DFID), the study consists of two phases. The first is an exploratory phase in which family planning providers accumulate enough first-hand experience to be able to identify strategies for overcoming potential difficulties associated with the introduction or delivery of emergency contraception services. The second phase, which began in March 1998, consists of individual operations research studies designed to test the problem solving strategies identified during Phase One.

Phase One of this study has involved five of Zambia's major providers of reproductive health services. These include University Teaching Hospital, fifteen health centers within the Ministry of Health/Central Board of Health, four clinics operated by the Planned Parenthood Association of Zambia, and the main campus clinic of the University of Zambia. Through the involvement of these groups, emergency contraception services are now available at more than 21 health care facilities across Lusaka and the rural Copperbelt.

\footnotetext{
${ }^{4}$ Population Council support to this study is made possible through a subgrant to UTH under the USAID Africa OR/TA II Project; and through technical support under the Council's Cooperative Agreement with USAID.
} 


\section{Project OutPuts and Data Collection ACTIVITIES}

The first phase of the project has entailed three major sets of activities: provider training; the delivery of emergency contraception services; and the collection of service statistics and other data on potential and actual users of emergency contraception services. To date, five data collection activities have been undertaken, each one designed to better our understanding of the broad theme areas discussed in the previous chapter. Data collection has included interviews with 400 termination of pregnancy clients at Lusaka's University Teaching Hospital $^{5}$; surveys among 52 health care providers and 1,600 clients of MCH/FP services; and focus groups among 46 students at the University of Zambia. In addition to surveys, client history records were also opened for all women receiving emergency contraception. All data collection activities undertaken in this study were reviewed and approved by the University of Zambia Research Ethics Committee.

\section{Provider Training}

Between July 9 and 23, 1997, 89 health care providers were trained in emergency contraception in three separate one-day workshops. The first, held in Lusaka, was attended by 23 participants, including five obstetrician/gynecologists, one health clinic manager, and 17 family planning nurse practitioners from nine family planning clinics across urban Lusaka.

The second workshop was held in the northern Zambian city of Ndola and included 26 nurse/ family planning practitioners, most from 11 health centers situated across Ndola Rural District. These health centers were selected for training partly because of their rural population base, but also because of their involvement in a separate operations research study, also funded by the Population Council and WHO, to enhance contraceptive choice through the expansion of underutilized methods.

Finally, on July 23, a third workshop was held to train 40 Lusaka-based health care providers not involved in the initial workshop. Held at UTH, the workshop was attended by four postgraduates in obstetrics and gynecology, two tutors in the UTH School of Nursing and Midwifery, one trainer from Population Services International (PSI) and 33 nurse/family planning practitioners.

All three workshops utilized the same materials and training format. Training materials were drawn from the packet developed and published by the Consortium for Emergency Contraception. Each participant was also provided with a complete set of materials for use during the training and to keep as a permanent reference source. Finally, a locally produced pre-test and post-test instrument was used to evaluate technical knowledge. All training activities were funded through a grant from the Canadian Public Health Association.

\footnotetext{
${ }^{5}$ The passage in 1972 of Zambia's Termination of Pregnancy Act legalized abortion on mental as well as health grounds. Under the Act, eligibility for termination of pregnancy services requires the prior authorization of three physicians, one of whom must be a specialist.
} 


\section{DELIVERY OF EMERGENCY CONTRACEPTION}

A fundamental premise of WHO's Strategy for Contraceptive Introduction and Technology Transfer is that any new method must be provided within the context of a broad contraceptive choice so that the focus of the introductory effort is not on one single method, but on the strengthened delivery of all methods. From the very outset, this study has adhered closely to this philosophy and has trained and equipped only those providers and health facilities capable of offering their clients a full range of reversible and permanent methods. ${ }^{6}$ Secure in the knowledge that emergency contraception would be provided within the context of broad method choice, at the conclusion of the each training workshop providers were given a supply of PC-4 for distribution at their respective health centers. To date, over 400 packets have been dispensed through the project, with distribution levels peaking and then declining after the first four months of the project. According to providers, the decline in distribution can be directly attributed to a more accurate understanding by clients of the appropriate usage of emergency contraception in general. Despite extensive counseling about the narrow 72-hour period within which emergency contraception must be begun, many providers claimed that the initial surge in demand for PC-4 was directly related to a widespread misperception among clients that the method might still be effective even beyond its recommended time frame. The decline in demand, they argue, was the gradual result of continued IEC efforts and simply the personal experience of those who had used it unsuccessfully.

\section{FIGURE 1}

\section{DISTRIBUTION OF EMERGENCY CONTRACEPTION AT PARTICIPATING CLINICS IN LUSAKA}

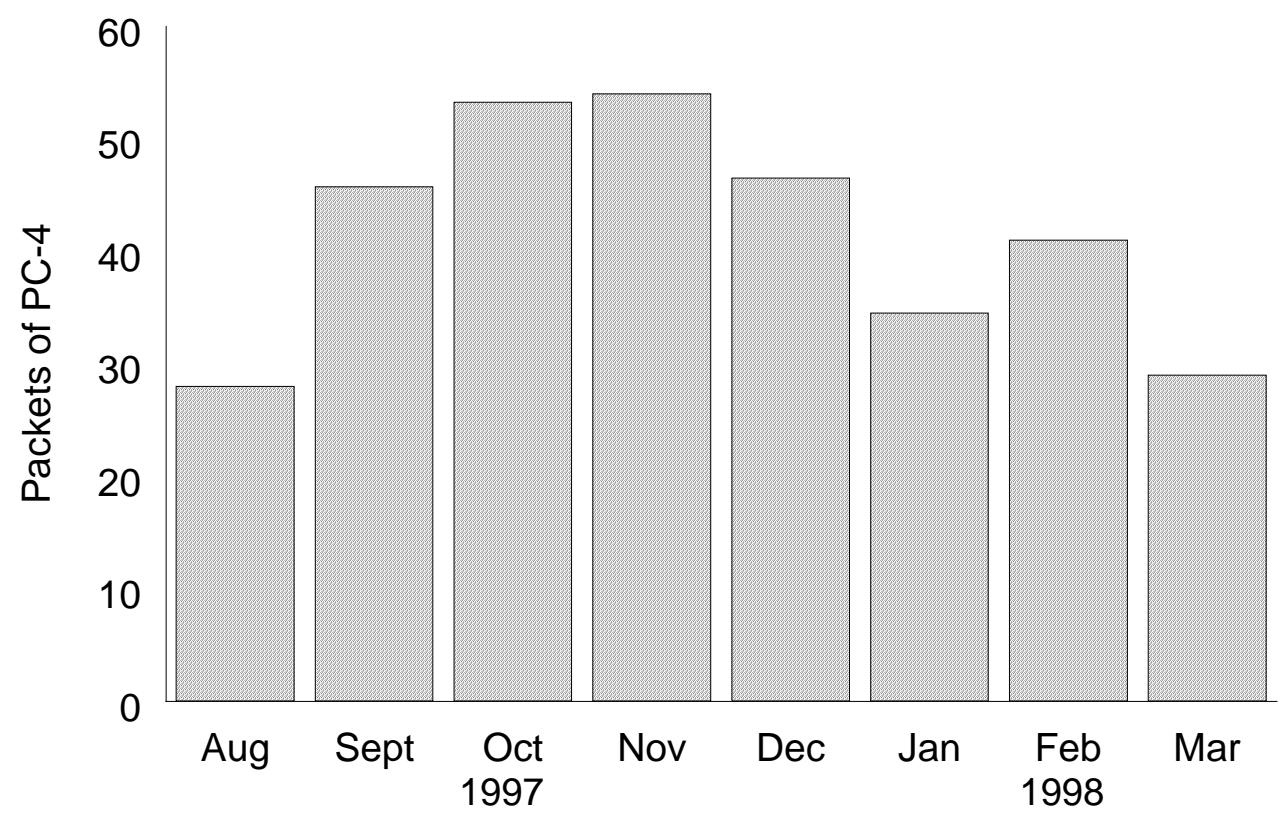

\footnotetext{
${ }^{6}$ All health centers - including those in Ndola Rural - offer their clients a full range of reversible methods. Permanent methods and longer-term methods such as Norplant ${ }^{\circledR}$ implants and the IUD are also available, either on site or through referral.
} 


\section{DAta Collection}

Survey Among Termination of Pregnancy Clients: This study is unique insofar as it represents the first time an emergency contraception survey has been carried out among abortion clients in a developing country. From August 8, 1997 to January 28, 1998, a structured questionnaire was administered to 400 women admitted to UTH for termination of pregnancy (TOP) under Zambia's 1972 Termination of Pregnancy Act. The survey consisted of two parts. In the first, respondents were asked general questions about their reproductive intentions, the circumstances surrounding their current unwanted pregnancy, their familiarity with emergency contraception, and their knowledge and use of family planning in general. During the second half of the survey, those not familiar with emergency contraception were briefly informed about it. They were then asked to reflect back upon the circumstances surrounding their current pregnancy to determine whether, knowing what they knew now, emergency contraception would indeed have been a viable option for them.

The impetus behind the survey of TOP clients was twofold. First, it was designed to overcome the hypothetical character of most existing surveys on emergency contraception where respondents are asked to reflect upon hypothetical situations - typically single acts of unprotected sex - and then surmise how they would respond to them. The second reason for surveying TOP clients was that by allowing women to reflect upon the concrete events and circumstances surrounding their own unwanted pregnancy, the study would be in a position to understand better not just whether emergency contraception is perceived by them as being "good or bad", but rather what the barriers to accessing it really were (Skibiak et al., 1997).

MCH/FP CLIENT SURVEY: The second major data collection activity undertaken during this study was a survey of 1600 women attending MCH/FP services at the four Ministry clinics (Chipata, Chawama, Mtendere and Kanyama) in Lusaka and the four Lusaka-based clinics of PPAZ (Lusaka, BB Camp, Kabanana and Ngombe).

Unlike the survey of TOP clients which was specifically oriented towards identifying barriers to emergency contraception use, the major objective of the $\mathrm{MCH} / \mathrm{FP}$ client survey was to assess knowledge, beliefs, and sources of information about the broad range of strategies currently used to prevent unwanted pregnancy in general. Though clients were given a description of emergency contraception and asked to indicate whether they might ever use it, of greater importance were the open ended questions that allowed the study to gauge what different client populations (family planning users, non-users, etc.) found most intriguing about emergency contraception, and the range of persons they felt they could turn to for information about it.

Provider InTerviews: From January 6 to February 11, 1998, interviews were carried out among 52 providers from each of the Lusaka-based facilities involved in this project. These included the four Ministry facilities, and the main clinic at PPAZ and UTH. Though originally intended to assess changes in staff knowledge and attitudes about emergency contraception over the course of the project's initial phase, the pre- and post-intervention design was dropped in favor of a single open-ended questionnaire administered at the end of Phase One. In doing so, the focus shifted away from measuring changes in provider knowledge and instead was 
reoriented towards discerning service delivery patterns that might be attributed to provider attitudes and biases ${ }^{7}$.

During the interviews, providers were asked to reflect upon overall use patterns of emergency contraception at their clinic; the circumstances under which they recommend emergency contraception; when they do not; and what they see its shortfalls to be.

Focus Group Discussion Among University Students: In January, 1998, four focus group discussions were carried out among 46 male and female students at the main and Ridgeway (medical school) campuses of the University of Zambia (UNZA). The decision to single out university students, as opposed to other youth groups, was motivated by two factors. First, at the outset of this project it was anticipated that, as is the case in many developed countries, the greatest demand for emergency contraception would be found amongst students - particularly students who do not typically live with their parents, are better educated than their age peers, and whose level of sexual activity is high, but irregular. Second, the results from these focus groups were intended to guide improvements in the delivery of reproductive health care services at the university's student health center, a participating agency in this project.

Discussions sought to explore knowledge of family planning in general, the range of factors influencing selection of service delivery providers or outlets, and recommendations as to how the delivery of emergency contraception as well as routine family planning services might be organized so that students have better access to appropriate follow-up and counseling.

Client History FORMS: As noted previously, approximately 400 women have been provided packages of PC-4 through this project. Initially, to avoid duplication and excessive paperwork, service statistics on emergency contraception use were recorded using only standard Ministry of Health reporting formats. Unfortunately, practical difficulties associated with routine data entry and analysis made it necessary to develop new data collection instruments that could be completed on site and turned over to the project for processing on a routine basis.

Introduced at all participating service delivery points in early December, the client history consists of three parts. The first examines the circumstances surrounding the act of unprotected sex that ultimately prompted the client to request emergency contraception. The second part is completed during the initial follow-up visit and seeks information on such factors as side effects, effectiveness, and general attitudes towards PC-4. The third section records whether the client chose to adopt a routine family planning method, what that method was, and the circumstances surrounding that decision.

Client history forms are opened for each person receiving emergency contraception. Each form is kept at the service delivery point until the client returns for her follow-up, and the last two sections can be completed. All completed forms are then turned over to the project for data entry.

\footnotetext{
7 Because Phase One providers were so closely involved in the development and implementation of project activities, it was eventually decided that measuring their knowledge about emergency contraception over time would not serve as a reliable indicator of knowledge loss or retention among providers in general.
} 


\section{RESEARCH FINDINGS AND PROGRAMMATIC IMPLICATIONS}

The data collection activities undertaken during Phase One of this study were designed to expand the existing knowledge base on five broad theme areas that have, at least in the developed world, attracted the bulk of research on emergency contraception. As noted previously, these themes include the issue of accessibility, which addresses both physical access to emergency contraception and access to the appropriate information a user must have before she will seek it out. The themes also include product administration which relates to the effect of product packaging and dispensing on the ability of women to access emergency contraception within the narrow 72 hour window of opportunity. Other issues of importance include the identification of appropriate strategies for managing side effects, for encouraging the transition from emergency contraception to routine use of family planning methods, and, finally, for the training of a potentially wide range of service providers.

This chapter examines these five themes with a view towards determining whether the issues in question really are relevant in a developing country context and, if so, what the programmatic implications of these findings might be, either in terms of subsequent research or simply in terms of future action. Each section, therefore, is divided into three parts: 1) a discussion of each theme area and the key assumptions underlying it; 2) a review of research findings as they relate to each assumption; and 3) the identification of programmatic implications that derive from the research results. 


\section{ACCESSIBILITY}

Random interviews carried out during the 1995 Zambia Contraceptive Needs Assessment (WHO 1995) suggest that even among women who fear they could become pregnant after unprotected sex or method failure, very few seek immediate advice or information from health care providers. One possible reason for this is that few women realize contraceptive options even exist after unprotected sex. Increasing accessibility to emergency contraception, therefore, not only entails enhancing physical access to a product, but also expanding access to the information a user must have before she will seek out the product in the first place.

At the outset of the current project, it was assumed that physical access to services would vary depending on the social, economic and personal circumstances of women who wished to use it. In the case of routine clients of family planning services, for example, accessibility was assumed to depend largely on the availability of traditional service delivery points such as clinics; whereas for others, such as younger or unmarried women, access might very well have been more a function of privacy. Unfortunately, the limited experience in Zambia with emergency contraception meant that few providers really understood what the principal barriers to such services actually were. A principal goal of this project, therefore, was to determine the most appropriate institutional channels for enhancing access, given the diverse constraints faced by different groups of women.

Just as important as enhancing access to emergency contraception services, however, was determining how best to disseminate information about it; and secondly, what the contents of that information should include. At least three factors were assumed to play a major role in this process: One was the source or institutional channels through which emergency contraception services would be provided (clinics vs. non-traditional outlets such as pharmacies or community based distributors); the second was the manner of administration and knowledge requirements associated with it (prophylactic distribution with self-administration vs. distribution as needed by health care personnel), the third was the prevailing knowledge and attitudes of different groups of women.

During the first phase of this project, therefore, data were collected to test the validity of a number of assumptions underlying strategies for enhancing access to both emergency contraception services and information. This section takes a closer look at these assumptions and, in the light of existing research, reviews a number of programmatic implications associated with them.

\section{DO AGE OR CIVIL STATUS INFLUENCE ACCESS TO SOURCES OF EMERGENCY CONTRACEPTION?}

A key objective of the present study was to determine which institutional channels would be most appropriate for enhancing physical access to emergency contraception by different groups of women. Obviously, such an objective assumes that physical access is likely to vary substantially with the different social, economic, and/or personal circumstances of women. Is this a valid assumption? At least three sets of data collected under this project suggest that physical access to emergency contraception does indeed vary with such factors such as age, conjugal status, and even prior use of family planning methods. One such set of data are the clinical records of 316 women who were provided PC-4 through this project from September 1997 through January 1998. All of these women received emergency contraception in a 
traditional, clinic-based setting operated by one of the four participating agencies in this project: UTH, MOH, PPAZ and UNZA. A closer look at those who received the method, however, reveals a population quite different from the young, nulliparous, unmarried, nonfamily planning users the study originally expected to manifest the greatest unmet need for emergency contraception. As it turns out, the mean age of emergency contraception users under this project was just over 29 years, with a range from 19 to 43 years. Emergency contraception users also reported an average of 2.9 previous pregnancies. And even more indicative of the skewed population served by these traditional $\mathrm{MCH} / \mathrm{FP}$ clinics is that fact that a surprising 58.6 percent of all PC-4 recipients reported to have been using some form of contraception at the time they had unprotected sex.

What, then, do these figures suggest? For one thing, they suggest that potential demand for emergency contraception is broad, and is not restricted to any single population group such a youth, unmarried women or non-users of family planning. But by the same token, it is also clear that the institutional channels adopted in Phase One of this project effectively excluded youth and, for that matter, a host of the other potential target groups. Not only are youth not represented among the users of PC-4, they also make up a very small percentage of clients at the clinics themselves. Youth aged 19 and below, for example, make up only 14.2 percent of $\mathrm{MCH} / \mathrm{FP}$ clients at the four MOH clinics, and less than 3 percent of clients at the PPAZ clinics. This pattern is also reflected in the average age of $\mathrm{MCH} / \mathrm{FP}$ clients, as illustrated below in Figure 2.

\section{FIGURE 2}

\section{MEAN AGE OF MCH/FP CLIENTS AT PARTICIPATING HEALTH FACILITIES}

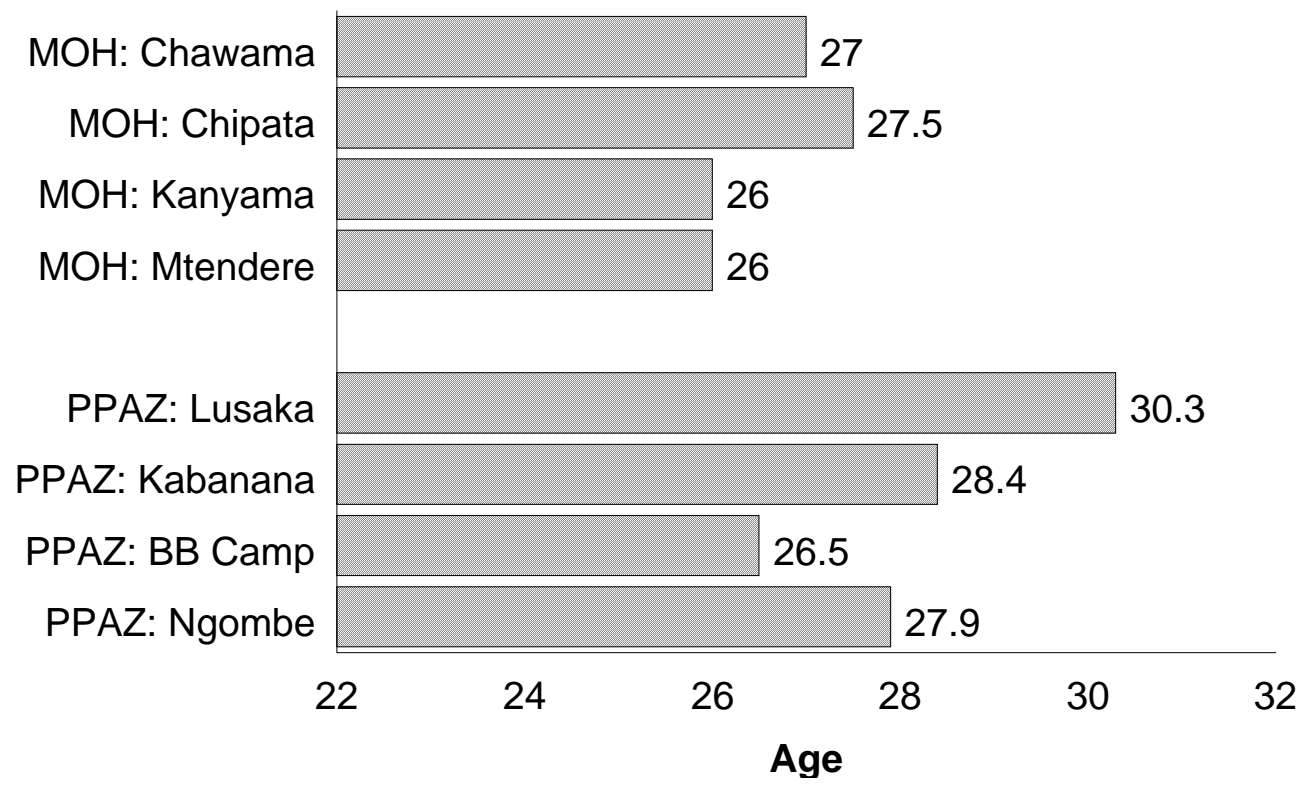

Another source of information suggesting a linkage between age and access to emergency contraception are the results of focus group discussions carried out among 46 male and female students at the main and Ridgeway (medical school) campuses of UNZA. During discussions on preferred sources of family planning services and information, the students were unanimous in wanting a "private place where they would not be known". Indeed, it was the perceived lack of privacy that discouraged students from seeking assistance at either the 
counseling centers or clinics of their respective campuses. Those from the medical school, for example, argued that anyone seeking services on campus would invariably run the risk of their "fellow students knowing their sexual life which is supposed to be confidential. They will be thinking that you have a big sexual problem." Others were even reluctant to go to UTH itself:

My lecturers and fellow students will know. I cannot compromise my private life. I would rather keep my private life private. There is also the thing whereby someone just looks at you and can't give contraceptives saying, 'You are only in fourth or fifth year.'

At UNZA's main campus, the story was similar. Though the students were aware that family planning clinics were held on Wednesday afternoon, they said the services were underutilized because "most students don't want to be seen to be interested in family planning for fear of being labeled promiscuous". Other obstacles cited were the attitudes of the clinic staff themselves:

The problem is that the nurses at the clinic are not friendly. I went myself to have an injection but the nurse told me 'You have already had it at your age? You are too young. You may not have children when you finally want them.'

\section{Programmatic Implications:}

New channels for the distribution of emergency contraception must be sought if emergency contraception is to be made accessible to youth, to non-users of routine family planning methods, or to women who, because of parity or non-marital status, do not attend traditional, clinic-based MCH/FP services.

$\checkmark$ Based on the youth comments during the focus group discussions, new outlets of both information and PC-4 could include chemists, on-campus peer counselors, circles of friends - and even the mini-mart at UNZA main campus. Interestingly, community based distributors or health educators were not seen as viable outlets; first because of a perceived lack of technical competence; and second, because of the lack of privacy.

\section{IS PRIOR KNOWLEDGE ABOUT EMERGENCY CONTRACEPTION A PREREQUISITE TO ITS USE?}

Another key objective of the present study was to determine how information about emergency contraception might best be disseminated and what the contents of that information should include. Both of these objectives rested on a series of assumptions regarding the importance of prior knowledge of emergency contraception as well as the belief that informational needs, like physical access, would vary depending on the attitudes and interests of different groups of women; on the different institutional channels through which services would be delivered; and on the manner in which emergency contraception was administered.

The view that one must first know about emergency contraception before one will seek it out is based on the assumption that most women believe there is little that can be done to avoid pregnancy once unprotected sex has occurred; hence the lack of interest in seeking out help. 
But the fact of the matter is that almost half of all 1,600 women interviewed at $\mathrm{MCH} / \mathrm{FP}$ clinics do believe there are indeed effective ways to avoid pregnancy, even after unprotected sex. True, these methods generally entail the ingestion of some substance to induce menses, but any notion that women are completely fatalistic about the prospect of becoming pregnant, is simply not true. ${ }^{8}$

Clearly, prior knowledge of emergency contraception is an important factor in enhancing accessibility to the product -- but it is doubtful whether such knowledge could truly be called a prerequisite to its use. A quarter (24.3 percent) of all women receiving emergency contraception through this project, for example, reported not to have known, prior to arriving at the clinic for care that it was possible to prevent pregnancy after unprotected sex. Obviously, the question arises, how did these women eventually learn about PC-4 at the clinic?

FIGURE 3

INCREASE IN RECOGNITION OF EMERGENCY CONTRACEPTION AS A MEANS TO AVOID PREGNANCY AFTER UNPROTECTED SEX

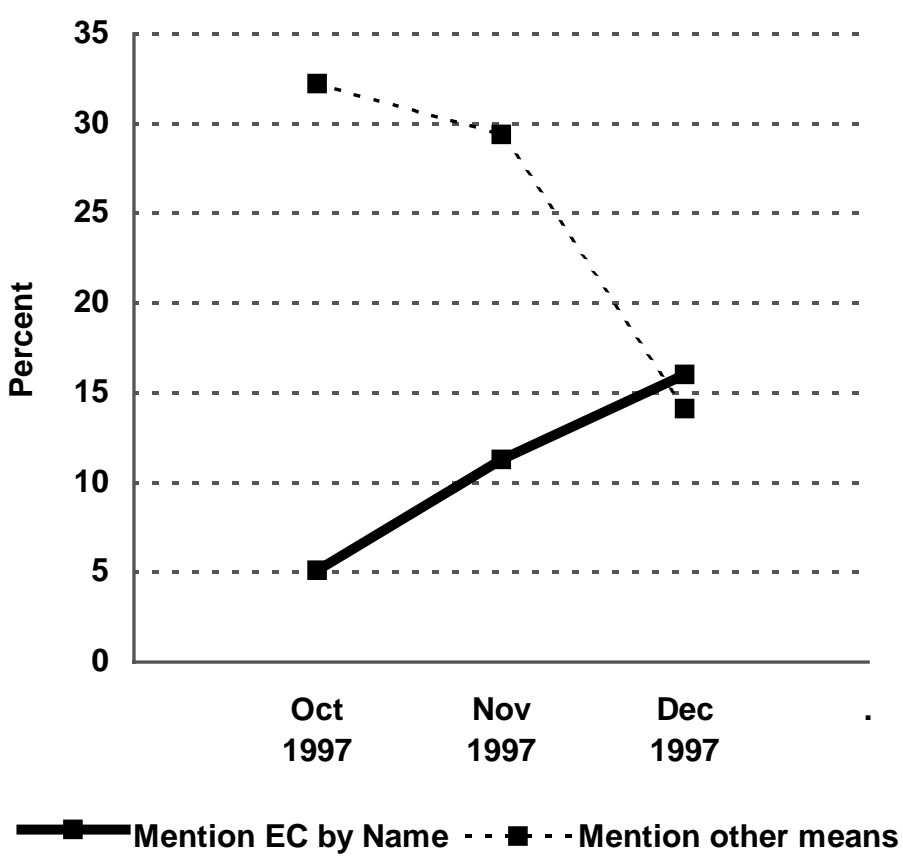

One factor, that may have confounded our own results was the administration of 1,600 $\mathrm{MCH} / \mathrm{FP}$ client questionnaire over the period September - December, 1997. Though designed to solicit knowledge and attitudes about emergency contraception, there is little doubt the instrument itself served as an extremely effective means of communicating information about the product, not only amongst $\mathrm{MCH} / \mathrm{FP}$ clients, but also amongst the community at large. Indeed, as Figure 3 indicates, the percentage of women identifying emergency contraception as a means of avoiding unwanted pregnancy after unprotected sex grew considerably over the three month period during which the questionnaire was administered. But even more

\footnotetext{
${ }^{8}$ Options mentioned included taking overdoses of a drug or chemical (21.4 percent), getting an abortion (4.9 percent), using traditional methods to abort (23.2 percent), taking an overdose of birth control pills (15 percent), and finally, use of emergency contraception (18.6 percent).
} 
important for the present discussion, is the possibility that the questionnaire served as a "trigger" or "on-the-spot" source of information for women who, though unaware of its existence beforehand, were in a position to have actually benefitted from it.

\section{Programmatic Implications:}

$\checkmark$ Efforts must be made to ensure that information about emergency contraception is communicated to the population at large. This means that in addition to directing inhouse IEC efforts towards those who are already using MCH/FP services, efforts should be made to reach those who do not regularly attend traditional clinic facilities.

$\checkmark$ In developing IEC strategies, health care centers must also ensure that mechanisms are in place to communicate "on the spot" information about emergency contraception, even to those who may be unaware of it when they arrive. The strategies need not be cumbersome or labor intensive: they may consist of simple posters advising women to ask for further information in the event they have had unprotected sex within the last 72 hours.

\section{ARE ACCESSIBLE SERVICES AND ACCURATE INFORMATION ENOUGH TO ENSURE THAT WOMEN WILL USE EMERGENCY CONTRACEPTION SERVICES WHEN THEY NEED THEM?}

Most IEC efforts in the area of emergency contraception are predicated on the belief that women will readily identify the risk associated with a single act of unprotected sex and respond to it in an appropriate manner. Unfortunately, our research suggests that recognition of such risk is by no means universal or even widespread. Of the 263 TOP candidates who agreed to discuss the circumstances leading to their pregnancy, over three quarters (76.5 percent) had absolutely no idea they might become pregnant. Fourteen percent could not even identify the act of sexual intercourse that led to their current pregnancy. Interestingly, those least likely to suspect pregnancy were women who had never used a family planning method before. Those most likely to suspect pregnancy, on the other hand, were women who had used family planning at some point in the past, but not on the particular occasion they had had unprotected sex (see Figure 4).

\section{DO ATTITUDES AND INTERESTS OF WOMEN VARY WITH RESPECT TO EMERGENCY CONTRACEPTION?}

Judging from the open ended responses on the $1600 \mathrm{MCH} / \mathrm{FP}$ client questionnaires, women's interests in emergency contraception do vary widely. At a very general level, almost all women express concern over such broad issues as potential side effects; how emergency contraception works in the body; its accessibility; how it relates to more routine family planning methods; its perceived potential as an abortifacient; its social consequences; and its role in protecting against STDs, including HIV/AIDS. But within that broad spectrum, certain questions appear to be much more critical and much more pertinent for particular groups of women. Two factors were found to have particular bearing on the kinds of information women seek: current use of a family planning method and history of termination of pregnancy. 


\section{FIGURE 4}

\section{PERCENTAGE OF WOMEN WHO SUSPECT PREGNANCY \\ WITHIN 72 HOURS OF UNPROTECTED SEX}

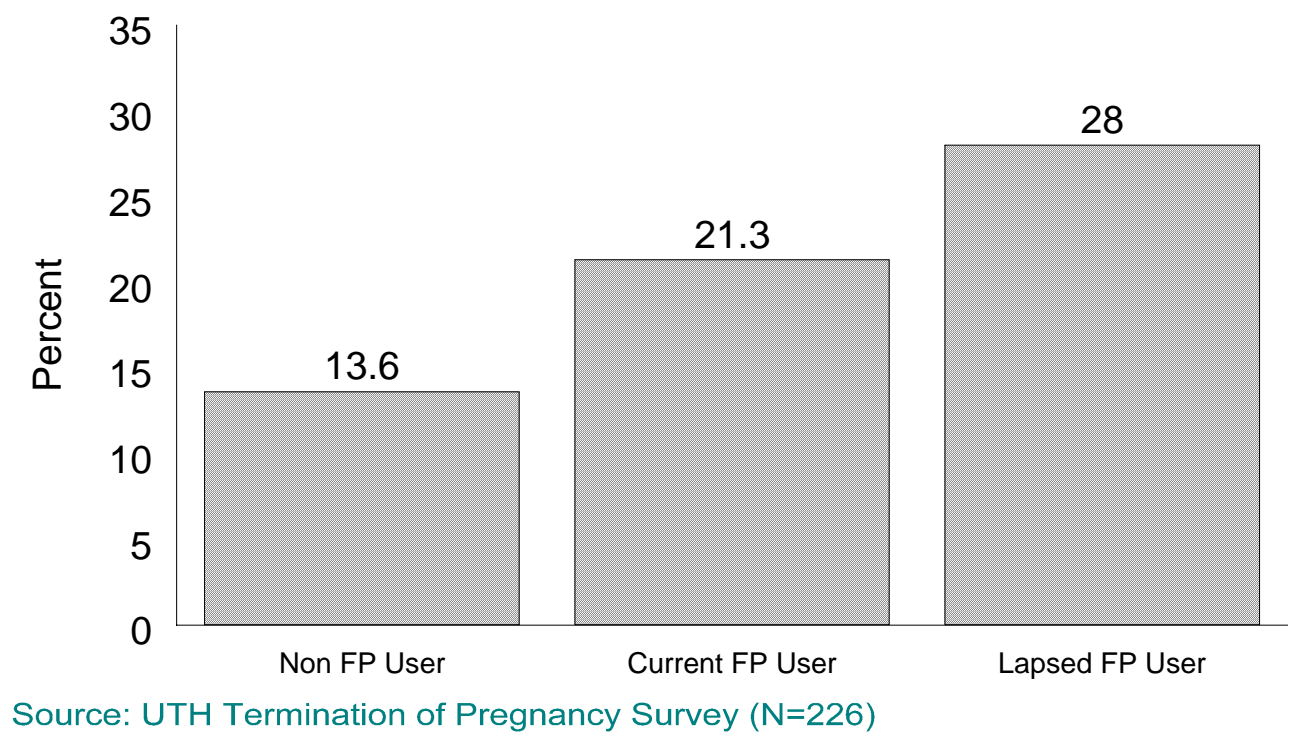

What is it about emergency contraception that interests family planning users the most? As already noted, continuing or lapsed family planning users are the two groups most likely to suspect they might be pregnant after an act of unprotected sex. It should come as no surprise, therefore, that relative to all respondents in general, these two groups are far more interested in knowing 1) how emergency contraception can lessen the likelihood of method failure (typically, by being used as an interim, back-up, or regular family planning method), and 2) given method failure, whether emergency contraception can still be of use (see Figure 5). Current family planning users, perhaps because they are already satisfied with one or more existing contraceptive methods, are also more likely to question the safety or what they perceive might be the "experimental nature" of emergency contraception. And finally, because they are already familiar with at least one contraceptive method, family planning users seem more interested than non-users in wanting to identify the most convenient sources for obtaining it. They are, for example, more likely than others to express an eagerness in being given PC-4 prophylatically in case of an emergency.

Non-users, by contrast, stand out more for their curiosity about the method itself: what it looks like, what its name is, what form it takes, and what else it does besides offering contraceptive protection. Non-users, for example, were virtually the only ones to ask whether PC-4 provided protection against STDs. Perhaps because non-users are statistically less likely than users to suspect pregnancy after unprotected sex, they show relatively little interest in knowing how emergency contraception relates to regular family planning use, or even whether emergency contraception can work beyond 72 hours after unprotected sex. 
FIGURE 5

EMERGENCY CONRACEPTION ISSUES OF PARTICULAR INTEREST

TO FAMILY PLANNING USERS

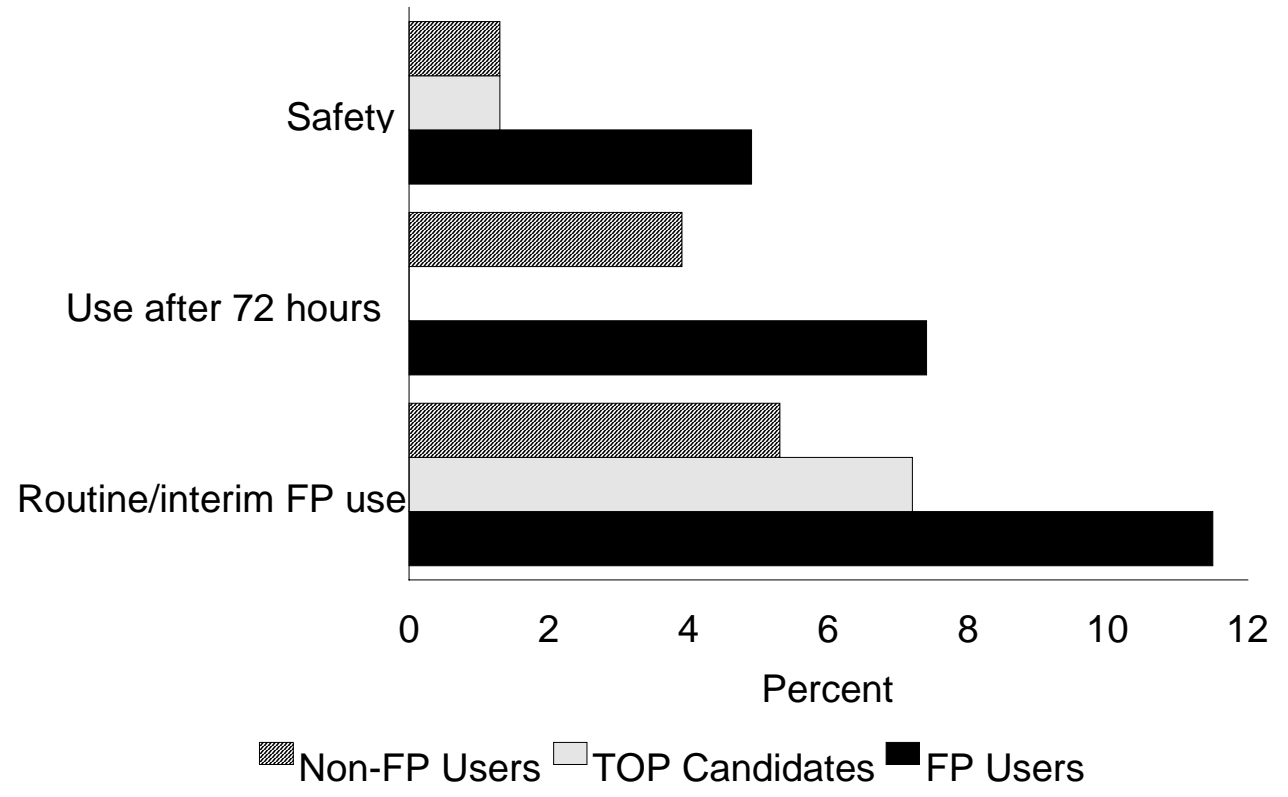

The third group to manifest a uniquely distinctive perspective on emergency contraception consists of women having just undergone a termination of pregnancy. While this group encompasses both women who were using a family planning method at the time they became pregnant (27 percent) and those who were not ( 73 percent), taken together, TOP candidates do present some striking differences with the $1600 \mathrm{MCH} / \mathrm{FP}$ clients (see Figure 6). Perhaps most noteworthy is the degree to which TOP candidates sought out information on where emergency contraception could be obtained and, in particular, on "confidential sources" such as private pharmacies. The former focus of interest can perhaps be accounted for by virtue of the different settings in which the interviews were carried out: TOP candidates were interviewed at the Obs \& Gynae Ward of UTH, while the $1600 \mathrm{MCH} / \mathrm{FP}$ clients were surveyed at the MCH/FP clinic of their local health center. Clearly, the latter group had less reason to ask about sources of emergency contraception, because they were already situated in a place where family planning methods in general are routinely distributed.

The importance of confidential sources, on the other hand, is probably attributable to the fact that TOP candidates reflected upon emergency contraception from the perspective of having recently undergone a termination of pregnancy - a deeply personal event that most women can be expected to want to keep private. In all likelihood, that same concern for privacy was probably transferred onto PC-4 insofar as it too, though not an abortifacient, would still have aided the women in avoiding the unintended consequences of unprotected sex. Their interest in confidential sources of product supply, therefore, was no doubt a reflection of that concern for privacy. The same is also true with respect to the group's interest in the cost of PC-4, an issue of relevance only if the women's intentions had been to obtain the product from an anonymous setting such as a pharmacy.

Finally, the third distinctive focus of interest on the part of TOP candidates was the immediate side effects of PC-4 use. While all women to some extent expressed an interest in 
this issue, none did so to the same degree as TOP candidates. Once again, however, that interest may very well have resulted from an interest in comparing the physical consequences of a termination of pregnancy, with that of PC-4.

\section{FIGURE 6}

\section{EMERGENCY CONRACEPTION ISSUES OF PARTICULAR INTEREST TO TERMINATION OF PREGNANCY CANDIDATES}

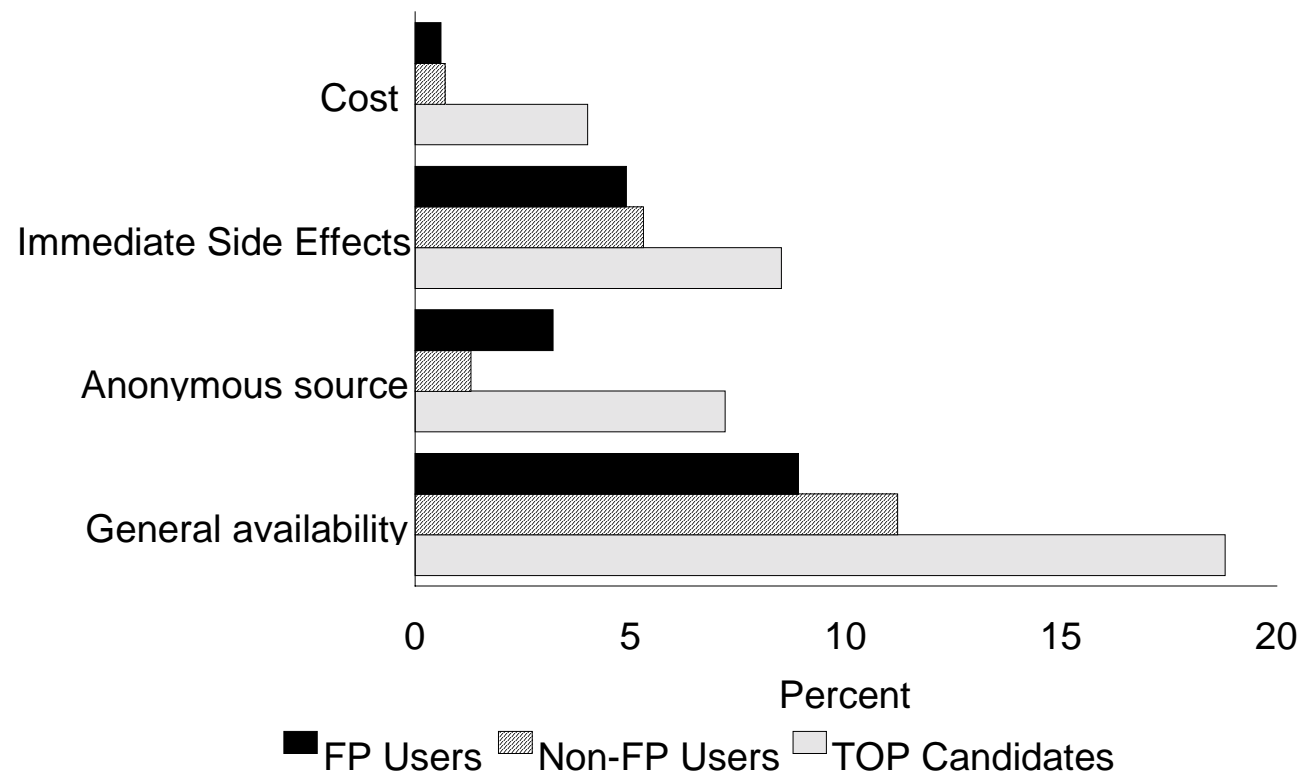

Programmatic Implications:

$\checkmark$ Efforts to communicate information on emergency contraception must, at the very least, recognize and build on a common set of issues that all potential users have found to be critically important. These include such issues as potential side effects; how emergency contraception works in the body, its accessibility; how it relates to more routine family planning methods; its ineffectiveness beyond 72 hours after unprotected sex; its social consequences; and its role at protecting against STDs, including HIVIAIDS.

$\checkmark$ In addition to addressing a common core of informational themes, health care providers and developers of IEC materials should gear their communication efforts to meet the specific needs and interests of different target populations. More pointed or directed informational efforts may be more effective in attracting and maintaining interest in emergency contraception. 


\section{ADMINISTRATION}

One distinctive feature of emergency contraception is the fact that although it can be considered "new" in the sense that it is unknown by the majority of family planning providers in Zambia, its use does not actually entail adoption of a new technology per se. The Yuzpe formulation, as noted earlier, simply entails the staged administration of four high dose oral contraceptives within a 72 hour time frame. This situation -- the novel application of existing technologies -- is perhaps unique in the family planning field and of course has major implications for the ways in which emergency contraception is administered by health care providers and used by women.

In the previous section we discussed the ways in which certain sociocultural or institutional factors can limit access, either to the product itself or to the information a woman must have before she can access it. Another barrier to emergency contraception, however, is what might be called a "time barrier" - essentially any hindrance or obstacle that delays a woman from accessing emergency contraception within the narrow 72 hour window available to her, irrespective of the institutional channels or sources through which the product (or information about the product) was originally obtained: clinic, pharmacy, peer counselor, etc.

Alternative strategies for administering emergency contraception provide perhaps the most effective means for breaking down these so-called "time barriers". One option, commonly employed in developed countries, is to administer emergency contraception prophylactically, that is to provide women with the appropriate number of oral contraceptives before they ever need it. This could vary from providing women with a dedicated product (oral contraceptives packaged exclusively for emergency contraception such as PC-4), to distributing coupons that can be redeemed anonymously in a pharmacy, to simply informing regular pill users (who can be expected to already have oral contraceptives on hand) of the Yuzpe regimen in case they discontinue using contraceptives.

Unfortunately, past experience from the developing world provides little guidance on the feasibility or practicality of such alternative strategies for administering emergency contraception. For that reason, one of the principal objectives of this study was to examine the issue of time constraints and identify strategies that might be developed and introduced to overcome them.

\section{WHAT BARRIERS EXIST THAT PREVENT WOMEN FROM OBTAINING EMERGENCY CONTRACEPTION IN A TIMELY FASHION, EVEN IF THEIR ACCESS TO SERVICES AND INFORMATION IS ADEQUATE?}

One of the difficulties in gauging the impact of time constraints on accessing emergency contraception is the fact that the most of our knowledge about emergency contraception users is derived from those who were ultimately successful at obtaining it. Nonetheless, what we do know is that a sizeable proportion of the women who obtained PC-4 through this project, probably already had at home regular oral contraceptive pills that could have been used for emergency contraception. Based on client record forms, nearly a third of all women who received PC-4, claimed to have been pill users at the time. Similarly, of the 179 termination of pregnancy candidates who said they would have used emergency contraception had they known 
about it at the time, over 22 percent reported having had oral contraceptives at home. Since these women had probably just missed taking the pill for two days or more, it would not be unreasonable to assume that the majority of them still had some pills on hand. So it is indeed possible that informing regular pill users how to use oral contraceptives for emergency purposes, could be an effective strategy at removing "time barriers" - particularly in cases where traditional sources of the dedicated product (MCH/FP facilities, pharmacies, etc.) are closed.

Obviously, one of the concerns of this so-called self-administration is that women could too easily forget how many pills to take, how often to do so, and how early to start. But once again, interviews among $\mathrm{MCH} / \mathrm{FP}$ clients suggests that knowledge retention on emergency contraception regimens is remarkably high. Of the 19 percent of clients $(\mathrm{N}=129)$ who identified emergency contraception by name as a means of avoiding pregnancy after unprotected sex, 80 percent accurately described the number of pills needed, the frequency with which they should be taken, and time frame within which emergency contraception must begin.

Another option might be to provide women, on a prophylactic basis, with a dedicated emergency contraception product such as PC-4. This suggestion had been widely proposed by respondents to both the TOP and MCH/FP questionnaires. But, once again, there were serious concerns - particularly amongst service providers - that prophylactic provision might only encourage women to abandon regular family planning under the belief that emergency contraception would always be there "in an emergency". Does this concern have any empirical basis? To some extent it does. As already noted during the discussion on client interests in emergency contraception, over twelve percent of the inquiries made by family planning users related in some way to the use of emergency contraception as a convenient alternative to a regular family planning method, particularly during the transition period between injections or before beginning a new cycle of pills. While the side effects of emergency contraception are no doubt likely to discourage this view in the long run, there was widespread concern among the majority (58 percent) of health care providers that prophylactic distribution of emergency contraception would - at least initially -- have a negative effect on the use of certain family planning methods.

\section{Programmatic Implications:}

$\checkmark$ In light of client demand for prophylactic administration of emergency contraception, efforts should be made to at least explore the feasibility of this approach and its consequences with respect to correct usage of the method, abandonment of regular family planning use, etc.

$\checkmark$ Efforts should also be made to explore alternative strategies for removing barriers that only prolong the period of time women must wait for obtaining emergency contraception. Such strategies could include continuous provision of emergency contraception pills at all health care facilities (not just at specified times), written instructions to regular users of oral contraceptives on how existing pills could be used for emergency purposes, etc. 


\section{CLIENT FOLLOW UP AND MANAGEMENT OF SIDE EFFECTS}

The potential need for routine follow-up of emergency contraception clients is predicated on two assumptions: first, that the side effects associated with emergency contraception are severe enough to actually warrant it; and second, that there are adequate resources available at the service delivery level to provide follow-up, should it be required. This section examines both of these assumptions and reviews their implications for subsequent research and/or action.

In this study, two sources of data can be utilized to address the issue of follow-up and management of side effects: interviews carried out among providers and client records of all emergency contraception users. Under the project, all women receiving PC-4 are requested to return to the health facility for a follow-up visit, either at the resumption of their menstrual period or at any point after which they feel their period should have already begun. As noted previously, client records such as these enable the project to identify the circumstances surrounding the act of unprotected sex that prompted recourse to emergency contraception; the physical and psychological consequences of having used emergency contraception; and the outcome of the client's decision to adopt a routine family planning method.

\section{DO THE SIDE EFFECTS ASSOCIATED WITH EMERGENCY CONTRACEPTION USE IN ZAMBIA NECESSITATE ROUTINE FOLLOW-UP OF ALL WOMEN WHO TAKE IT?}

All hormonally-based emergency contraception regimens entail some side effects. Those associated with the Yuzpe regimen, for example, include the same range of effects commonly experienced with short-term use of combined oral contraceptives, though with higher frequency. One of the objectives of the present study, therefore, was to determine whether the side effects experienced in Zambia deviated in any way from those reported in the literature and, if so, what the implications of these deviations might be for the establishment of follow-up protocols.

Based on the 70 client history forms completed by the end of February, the range and severity of side effects associated with PC-4 use in Zambia are comparable to those described in the existing literature. ${ }^{9}$ One of the most widely cited sources of data on this topic is a 1993 study by Ho and Kwan which compared the side effects of two emergency contraception regimens:

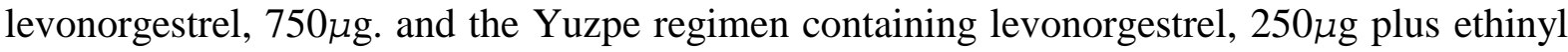
estradiol, 50 $\mu \mathrm{g}$. Figure 7, compares Ho and Kwan's data on the Yuzpe side effects with the results derived from the current study.

\footnotetext{
${ }^{9}$ Completed client histories refer to client cases in which health care staff have completed all three sections of the client history form. As noted previously, completed client histories would exclude those who received PC-4 before the current client history form was adopted as well as those who received PC-4 after the form was adopted, but who had not yet returned for their follow-up visit.
} 


\section{FIGURE 7}

\section{FREQUENCY OF SIDE EFFECTS ASSOCIATED WITH USE \\ OF EMERGENCY CONTRACEPTION (PC-4)}

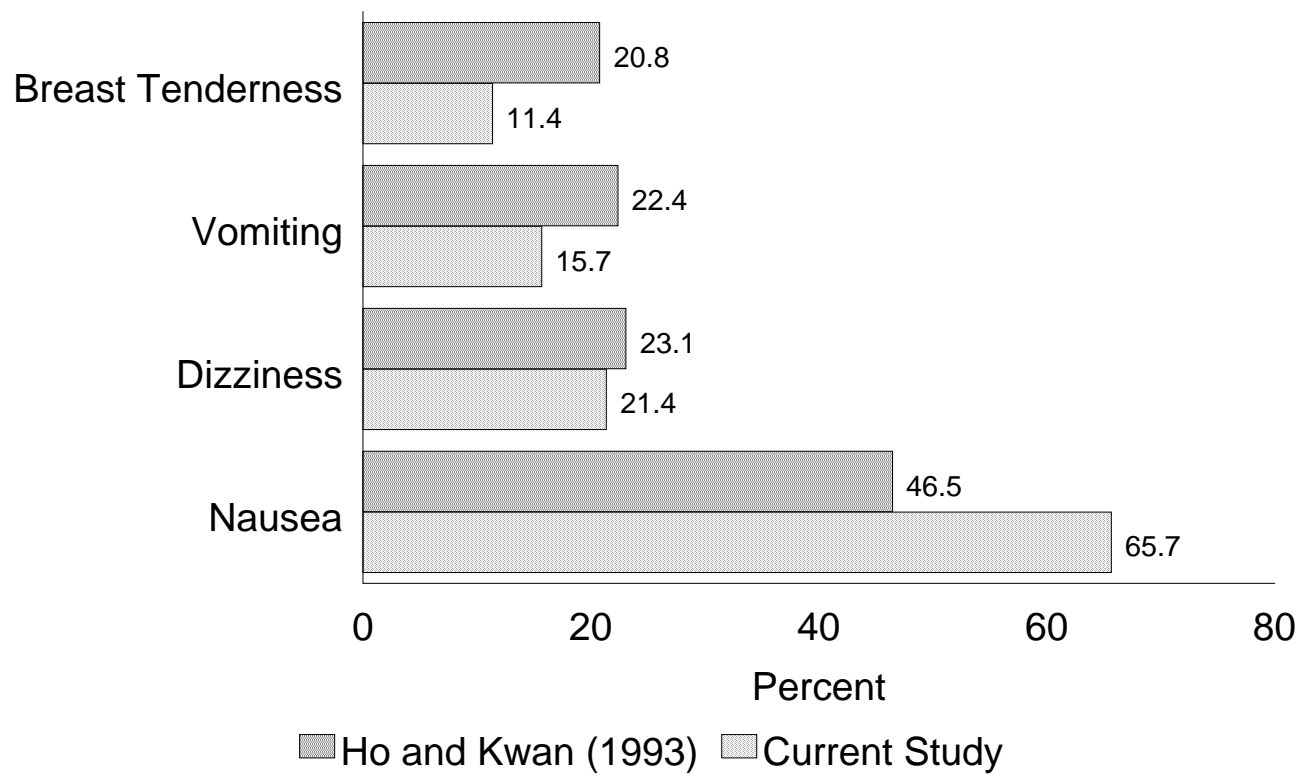

Though the range and degree of side effects observed in Zambia do correspond overall to those described by Ho and Kwan, one notable disparity is the frequency of nausea. While it is important to keep in mind that even Zambia's figures fall well within the range described by other reputable sources ${ }^{10}$, potential client fears over nausea could very well affect the demand for emergency contraception in general. ${ }^{11}$

Clearly, efforts must be undertaken to understand better the reasons for the reported levels of nausea. It may very well be that the discrepancy is simply a matter of definition: women who might otherwise have reported vomiting (which, incidentally, occurs less frequently than in Ho and Kwan's study), described their symptoms as nausea. Alternatively, it might be the case that in poorer countries such as Zambia, women are more likely to take emergency contraception on an empty stomach. Taking emergency contraception pills with food, for example, is believed to reduce the likelihood of side effects (Hatcher et al 1994: 443). Remedial strategies may include better counseling or even the introduction of a progestinonly emergency contraception method. Studies have shown that progestin-only regimens can significantly reduce the incidence of side effects. In Ho and Kwan's (1993) study, for example, nausea associated with the use of a progestin-only emergency contraception pill was reduced by as much as 65 percent, vomiting by 88 percent, dizziness by 20 percent and breast tenderness by 24 percent. One such method, containing levonorgestrel, $750 \mu \mathrm{g}$., has been chosen for use by the International Consortium on Emergency Contraception in its worldwide study on emergency contraception introduction and usage (see Figure 8).

\footnotetext{
${ }^{10}$ Hatcher et al (1994: 422) notes in the sixteenth revised edition of Contraceptive Technology that "[n]ausea occurs in 50 percent-70 percent of those treated".

${ }^{11}$ It is worth noting however, that despite the reported side effects, 97 percent of all PC-4 users who returned for their follow-up visit said they would still recommend emergency contraception to a friend.
} 
FIGURE 8

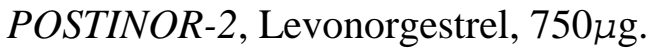

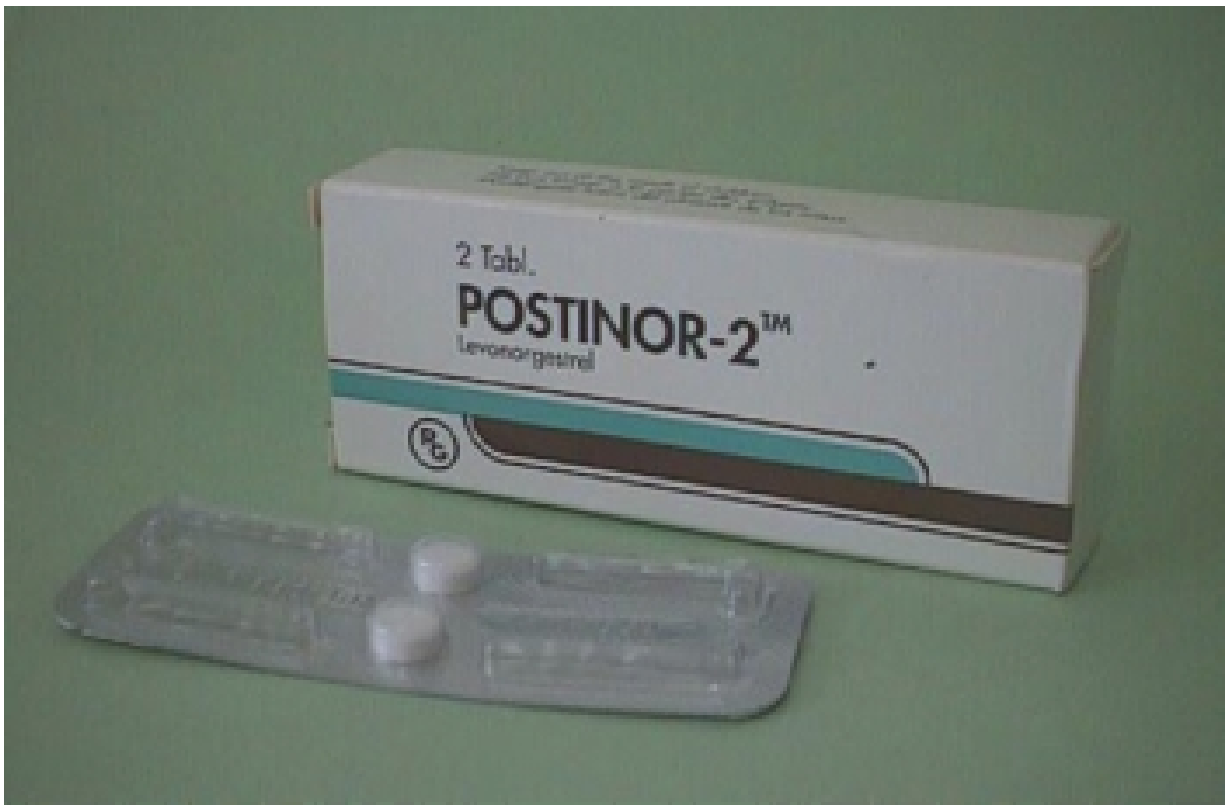

Programmatic Implications:

$\checkmark$ There is no indication that the side effects associated with use of emergency contraception pills warrant routine follow-up. Consequently, doubts or concerns over the feasibility of client follow-up should not, at least on medical grounds, play a role in hindering or limiting the provision of emergency contraception services.

$\checkmark$ While reported levels of nausea fall within the range described in the existing literature, they are still high. Efforts should be undertaken to understand better the reasons for these high levels and, if possible, to reduce them. One option may be to compare the side effects associated with $\mathrm{PC}-4$, with those of a progestin-only method.

\section{DO DEVELOPING COUNTRY SETTINGS PLACE UNIQUE CONSTRAINTS ON EFFECTIVE STRATEGIES FOR FOLLOWING-UP ON EMERGENCY CONTRACEPTION CLIENTS?}

In the developing world, overcrowded health care facilities, unreliable transport, scarce financial resources and a lack of effective communication channels have often been seen as impediments to any effective or systematic follow-up protocols. With respect to the delivery of emergency contraception, therefore, the question has often been asked whether these impediments - if they exist -- should in any way limit the provision of emergency contraception services.

As noted in the previous section, there is no evidence that the severity of side effects associated with use of PC-4 warrant any routine follow-up of emergency contraception 
clients. By the same token, however, the fact that 80 percent of women are likely to experience at least some side effects highlights the need to ensure that anyone seeking medical attention or even counseling has ample opportunity to obtain it.

One of the key objectives of this study, therefore, was to explore whether service delivery conditions in Lusaka do in any way present difficulties that might impede follow-up of emergency contraception clients. These difficulties could include restrictions on the ability of providers to contact clients, or constraints that might affect the ability of clients to return to health centers.

Service statistics and the detailed client record forms reveal that despite communication and other resource-related problems, return for follow-up at most Lusaka-based service delivery points is quite high. This point is illustrated in Figure 9, for example, where the number of clients returning for follow-up (within two months of their initial visit) at the four Ministry clinics is compared with the total number of those who received PC-4 between December 1, 1997 and January 31, 1998. ${ }^{12}$ While there are obvious differences in the rates of follow-up among the individual clinics themselves, overall nearly 90 percent of all emergency contraception clients are returning, at least 20 percent of whom experienced no side effects whatsoever.

\section{FIGURE 9}

\section{RETURN TO FOLLOW-UP \\ AMONG EMERGENCY CONTRACEPTION CLIENTS}

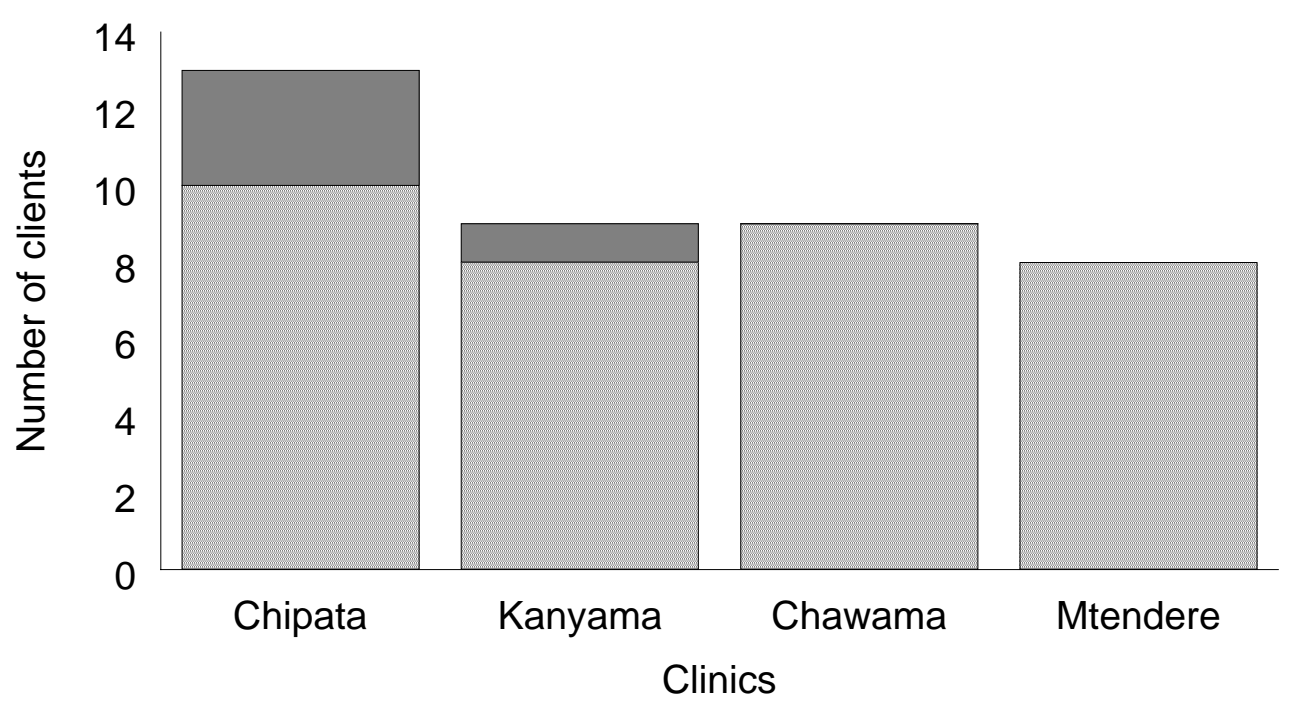

$\square$ Returned clients

\footnotetext{
${ }^{12}$ Because the current client history forms were not consistently applied at all service delivery points until December, 1997, data on client returns prior to that date remain incomplete. The end date of January 31, 1998 was chosen insofar as it represents the latest date to which the two-month "lost to follow-up" criterion can be applied (present data analysis was carried out after March 31, 1998).
} 
What do these high levels of return suggest? For one thing, they suggest that demand for follow-up services is probably not a "provider or project-driven" phenomenon. Clients are returning because they want advice on how best to handle side effects; or because they want confirmation that they are not pregnant; or because they want to know why, in some cases, emergency contraception did not work. As the delivery of emergency contraception pills expands to include non-clinical sources or services (see page 11), providers are likely to see an increase in persons seeking follow-up advice and counseling -- particularly amongst those who, because of confidentiality, may not have originally received emergency contraception pills from that particular health center (or from any health center at all if their source was a pharmacy or CBD agent). As the knowledge and utilization of emergency contraception expands, it will become increasingly important that providers become familiar with the method and that all health care facilities open their doors to meet the needs of anyone seeking follow-up.

Programmatic Implications:

Appropriate quality of care demands that the delivery of emergency contraception services should include provisions to ensure that any woman using the method has unrestricted access to medical follow-up should she desire it. 


\section{TRAINING}

Given the range of persons potentially qualified to offer emergency contraception, and the varying degrees of family planning knowledge and experience they possess, the issue of training is likely to grow in importance as emergency contraception increasingly becomes a routine part of the national method mix. Until then, however, it is probable that the training-related lessons from this study will continue to be derived less from the results of formal data collection activities, than from the simple day-to-day observation of service delivery facilities.

\section{ARE TRAINING STRATEGIES USED FOR ROUTINE FAMILY PLANNING ENTIRELY APPROPRIATE FOR EMERGENCY CONTRACEPTION?}

Earlier in this document, it was mentioned that the introduction of emergency contraception would, in all likelihood, entail uncertainties and questions for which the delivery of traditional family planning services would provide very few answers. One clear example of this is the range and number of clinic staff who must be familiar with emergency contraception if the method is truly able to fulfill its role as an immediate back-up in cases of unprotected sex. Initially, it was assumed that -- as in the case of most family planning training programs -training a selected number of $\mathrm{MCH} / \mathrm{FP}$ staff at each health center would be adequate to meet the needs of clients seeking emergency contraception services. For that reason, the project made no special provisions for these staff to disseminate information about emergency contraception beyond the ranks of those who were actually present at the original training course.

Unfortunately, the consequences of this oversight were evident almost immediately. During unscheduled visits to the participating clinics, project staff often encountered no one on duty with any knowledge of emergency contraception. Had anyone actually shown up in need of emergency contraception, not only would they not have received it, but they probably would have been given incorrect information. During the 1995 Zambia Contraceptive Needs Assessment, for example, the most common response cited by medical staff when confronted by a victim of sexual assault or unprotected sex was to tell her to "return after menses".

To alleviate this problem of limited staff knowledge, the project immediately offered assistance to any trained provider wishing to conduct an in-house training for the staff of their respective clinics. Support included the provision of reference and other training materials as well as technical advice in tailoring the original training curriculum to reflect local needs and time constraints.

While it is difficult to measure the impact of these in-house trainings on the actual provision of emergency contraception services, it is worth noting that the period in which the training took place (August to September) saw a 63 percent increase in the levels of PC-4 distribution. Whether the relationship was really causal is unclear. What is clear, however, is that by the end of Phase One, knowledge about emergency contraception was no longer the purview of a select number of providers. In interviews carried out amongst $52 \mathrm{MCH} / \mathrm{FP}$ providers at all participating service delivery sites, over 98 percent reported familiarity with method. 


\section{Programmatic Implications:}

$\checkmark$ Efforts should be made to ensure that knowledge of emergency contraception is widespread throughout any given health care facility. Not only is it critical that this include staff of MCH/FP units, but also anyone who could theoretically be expected to attend to victims of sexual violence or unprotected sex whenever MCH/FP facilities are closed.

\section{WHEN A METHOD IS NOT INTENDED FOR ROUTINE CONTRACEPTIVE USE, DOES THE DICTUM OF ENSURING BROAD METHOD CHOICE STILL HOLD?}

A key assumption of WHO's Strategy for Contraceptive Introduction and Technology Transfer (Spicehandler, Simmons et al: 1994) is that any new method must be provided within the context of broad method choice and that the focus of any introductory effort should not be on one single method, but on the strengthened delivery of all methods. From the very outset, this study has adhered closely to this philosophy by training and equipping only those providers and health facilities capable of offering their clients a full range of reversible and permanent methods.

What the results of Phase One indicate is that in the case of emergency contraception, the need for broad method choice may be even more critical than in the case of routine family planning services. Why is this so? Primarily because with emergency contraception, the importance of broad method choice derives not only from the desire to avoid provider biases in the method selection process (a common occurrence with any single method introductory effort), but because client records and KAP interviews suggest that family planning users are at high risk of choosing emergency contraception in lieu of regular family planning methods.

To ensure that emergency contraception does not become perceived as a contraceptive "quick fix", providers must be knowledgeable enough about the full range of family planning methods that they can discuss openly and accurately, the advantages and disadvantages of each. Of course the difficulty with this will become increasingly evident as efforts are made to extend emergency contraception to populations not typically served through static health facilities. As service delivery sources are broadened to include such nontraditional providers as pharmacists, community based distributors, or even peer counselors, the greatest challenge will be to determine the most appropriate role for each category of provider (as a purveyor of information, of services, or of both?) within an overall service delivery system; defining how that role can be articulated with those of others within the health care system; and developing a training program to ensure that even with specialization, users still have access to broad method choice.

\section{Programmatic Implications:}

$\checkmark$ Given the tendency of family planning users to view emergency contraception as an alternative to routine family planning use, training must ensure that emergency contraception is always provided within the context of a broad method mix. 
$\checkmark$ As the range of emergency contraception providers expands to enhance physical access to the product, there will be a need to develop new training curricula that reflect the different knowledge levels, time constraints, needs and unique characteristics of each provider group. 


\section{TRANSITION TO REGULAR FAMILY PLANNING}

Despite the relative efficacy of emergency contraception, most health care providers agree that it is a method that ought to remain precisely what its name implies, "emergency". To ensure this, however, emergency contraception clients must be afforded every opportunity to adopt a regular family planning method so that the limitations of emergency contraception (i.e. the importance of prior user-awareness, the short window of opportunity, the lower effectiveness of emergency contraception relative to many other contraceptives, and the unpleasant side effects) are reserved for the failure or non-use of more effective methods.

A major objective of the current study, therefore, was to identify what barriers, if any, might limit the ability of women to make the transition from emergency to regular family planning use. Such barriers could include, for example, limited information - particularly among those whose access to emergency contraception is through non-clinic sources. Or they could include missed opportunities for follow-up at traditional service delivery points.

Interestingly, what the survey results revealed was that a number of the assumptions underlying the "transition issue" were themselves flawed, largely because the project ended up serving a target population so different from the one originally envisioned. While these changes do not diminish the importance of assisting women to move from emergency to routine contraception, they do highlight the need to address this issue in a much broader manner.

\section{IS THE RELATIONSHIP BETWEEN EMERGENCY CONTRACEPTION AND REGULAR FAMILY PLANNING A ONE-WAY STREET?}

A basic assumption underlying concerns over the transition to routine family planning use, is that unmet demand for emergency contraception would be particularly high among nonfamily planning users. Another assumption is that routine use of a family planning method, by definition, would limit the need for emergency contraception in the first place. What the results of this study show, however, is that neither of these assumptions need necessarily be true.

Almost two-thirds (59 percent) of the women who received emergency contraception described themselves as regular family planning users. As one might expect, most of these were either condom users (37 percent) who had experienced breakage or users of oral contraceptives (29 percent) who had forgotten their pill for two days or more. But especially notable for the purposes of this discussion is the fact that despite being routine family planning users, many of these women expressed considerable interest in knowing how emergency contraception could be used in conjunction with, or in lieu of, their existing family planning method. Providers were repeatedly asked, for example, whether emergency contraception could be used as back-up for those using the rhythm method or whether it could be used by women awaiting their next injection or cycle of pills. In fact, the perceived convenience of emergency contraception relative to other routine methods was so striking that health care providers' main concern over prophylactic distribution of PC-4 was that users would be more inclined to discontinue their regular method, knowing they had a simple backup method on hand. 


\section{Programmatic Implications:}

$\checkmark$ While providing emergency contraception services, health care workers must recognize that users as well as non-users of regular family planning require counseling and support to ensure that emergency contraception is not seen as a "quick-fix" or that it is not adopted at the expense of more reliable methods.

\section{DOES THE EXPERIENCE OF HAVING USED EMERGENCY CONTRACEPTION ENCOURAGE THE ADOPTION OF MORE EFFECTIVE FAMILY PLANNING METHODS?}

It is ironic that while many routine family planning users seem attracted to the apparent convenience of emergency contraception, non-users who have actually experienced emergency contraception are virtually unified in wanting to begin routine family planning right away. Of the 29 non-family planning users to receive emergency contraception since December, for example, all but three (90 percent) eventually chose to adopt a routine family planning method. Moreover, the methods they chose were notable for their efficacy. Pills, the IUD, injectables and Norplant ${ }^{\circledR}$ implants represented over 92 percent of the mix. Interestingly, this mix stands in sharp contrast to that of the "regular family planning users", for whom barrier methods represented over half (51 percent) of their method mix.

Even amongst regular family planning users, however, emergency contraception use is strongly associated with the adoption of more effective contraception. Figure 10, for example, illustrates the shift in overall method mix among 51 routine family planning users before and after use of PC-4.

FIGURE 10

\section{METHOD MIX BEFORE AND AFTER USE OF PC-4}

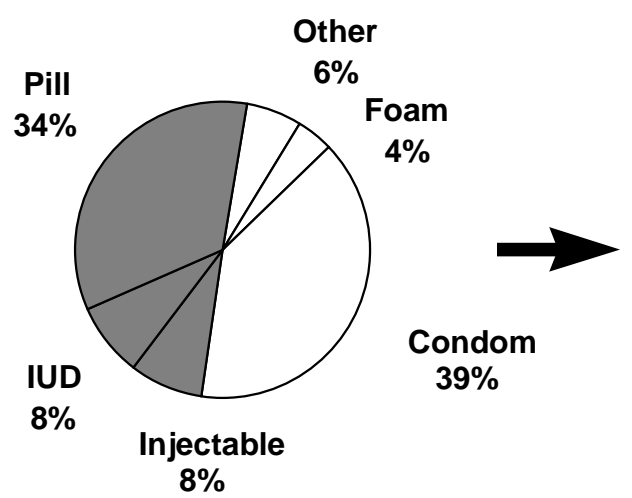

Barrier Methods

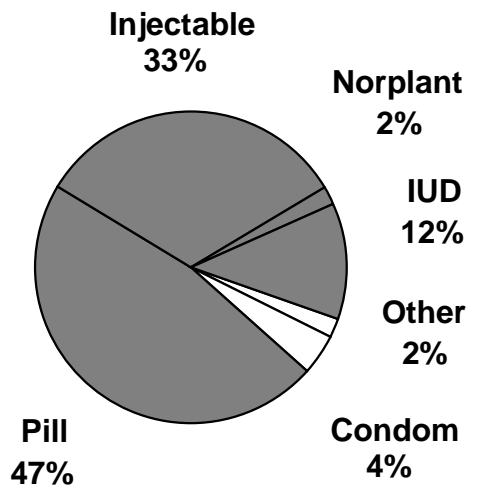

Non-barrier methods 
These results also cast doubt, however, on a widely held view that enhanced access to emergency contraception encourages wider use of barrier methods since it offers extra protection (and, therefore, an additional degree of security) in the case of method failure. While this may still be true for those who have yet to use emergency contraception, data from this study certainly do not suggest it to be the case with former PC-4 users.

\section{Programmatic Implications:}

Given the importance of condom-use for prevention of reproductive tract infections, including HIVIAIDS, it is critical that health care providers do not allow the apparent dissatisfaction with less effective methods to discourage condom use among former users of emergency contraception. Current efforts to promote dual protection should be reinforced.

\section{WHAT IS THE ROLE OF EMERGENCY CONTRACEPTION FOR THOSE WHO CHOOSE NOT TO ADOPT A REGULAR FAMILY PLANNING METHOD?}

A common perception among clients and family planning providers is that emergency contraception pills will protect a woman from pregnancy even if she engages in unprotected intercourse in the days or weeks following treatment. It will not. Another misconception is that emergency contraception pills typically cause a client's menses to come immediately. In reality, the timing is likely to vary by only a few days.

Since the use of emergency contraception always affects, to some degree, a woman's menstrual pattern, existing protocols recommend that anyone engaging in unprotected sex following treatment be encouraged to use a barrier method for the remainder of her cycle. Unfortunately, for those who choose not to follow this advice or for those who refuse to use a regular family planning method in general, these protocols pose a serious dilemma. For if emergency contraception really does preclude use of the method later during the same cycle, then the question arises whether use of emergency contraception should be reserved (in the case of non-users) for those circumstances where unprotected sex truly is likely to lead to pregnancy. As it stands now, existing service delivery protocols effectively limit the ability of emergency contraception to play a role in avoiding pregnancy among such women, since they fail to distinguish between those acts of unprotected sex that are statistically more likely to result in pregnancy (those that occur at mid-cycle), and those that are statistically less likely to result in pregnancy.

While there is a general acceptance within the reproductive health community that every effort should be made to enable users of emergency contraception to adopt a more effective family planning method, the fact remains that many women will not do so, for a variety of reasons. For these women, emergency contraception may indeed represent the only alternative to an unwanted pregnancy or unsafe abortion. Providers must, therefore, be equipped to improve recognition of reproductive risk by a wider dissemination of information on the menstrual cycle along with more effective explanations of the relative risks associated with unprotected sex at different points in that cycle. 
Programmatic Implications:

$\checkmark$ While efforts should be made to facilitate the transition from emergency to regular contraceptive use, service delivery protocols for emergency contraception should also respond to the needs of non-users of regular family planning methods or by women who chose to adopt emergency contraception as their "regular" family planning method. 


\section{SUMMARY OF PROGRAMMATIC \\ IMPLICATIONS}

\section{ACCESSIBILITY}

$\checkmark$ New channels for the distribution of emergency contraception must be sought if emergency contraception is to be made accessible to youth, to non-users of routine family planning methods, or to women who, because of parity or non-marital status, do not attend traditional, clinic-based MCH/FP services.

$\checkmark$ Based on the youth comments during the focus group discussions, new outlets of both information and PC-4 could include chemists, on-campus peer counselors, circles of friends - and even the mini-mart at UNZA main campus. Interestingly, community based distributors or health educators were not seen as viable outlets; first because of a perceived lack of technical competence; and second, because of the lack of privacy.

$\checkmark$ Efforts must be made to ensure that information about emergency contraception is communicated to the population at large. This means that in addition to directing inhouse IEC efforts towards those who are already using MCH/FP services, efforts should be made to reach those who do not regularly attend traditional clinic facilities.

$\checkmark$ In developing IEC strategies, health care centers must also ensure that mechanisms are in place to communicate "on the spot" information about emergency contraception, even to those who may be unaware of it when they arrive. The strategies need not be cumbersome or labor intensive: they may consist of simple posters advising women to ask for further information in the event they have had unprotected sex within the last 72 hours.

$\checkmark$ Efforts to communicate information on emergency contraception must, at the very least, recognize and build on a common set of issues that all potential users have found to be critically important. These include such issues as potential side effects; how emergency contraception works in the body, its accessibility, how it relates to more routine family planning methods; its potential as an abortifacient; its social consequences; and its role at protecting against STDs, including HIV/AIDS.

$\checkmark$ In addition to addressing a common core of informational themes, health care providers and developers of IEC materials should gear their communication efforts to meet the specific needs and interests of different target populations. More pointed or directed informational efforts may be more effective in attracting and maintaining interest in emergency contraception.

\section{ADMINISTRATION}

$\checkmark$ In light of client demand for prophylactic administration of emergency contraception, efforts should be made to at least explore the feasibility of this approach and its consequences with respect to correct usage of the method, abandonment of regular family planning use, etc.

$\checkmark$ Efforts should also be made to explore alternative strategies for removing barriers that only prolong the period of time women must wait for obtaining emergency contraception. Such strategies could include continuous provision of emergency contraception pills at all 
health care facilities, written instructions to regular users of oral contraceptives on how existing pills could be used for emergency purposes, etc.

\section{CLIENT FOLLOW UP AND MANAGEMENT OF SIDE EFFECTS}

$\checkmark$ There is no indication that the side effects associated with use of emergency contraception pills warrant routine follow-up. Consequently, doubts or concerns over the feasibility of client follow-up should not, at least on medical grounds, play a role in hindering or limiting the provision of emergency contraception services.

$\checkmark$ While reported levels of nausea fall within the range described in the existing literature, they are still high. Efforts should be undertaken to understand better the reasons for these high levels and, if possible, to reduce them. One option may be to compare the side effects associated with PC-4, with those of a progestin-only method.

$\checkmark$ Appropriate quality of care demands that the delivery of emergency contraception services should include provisions to ensure that any woman using the method has unrestricted access to medical follow-up should she desire it.

\section{TRAINING}

$\checkmark$ Efforts should be made to ensure that knowledge of emergency contraception is widespread throughout any given health care facility. Not only is it critical that this include staff of MCH/FP units, but also anyone who could theoretically be expected to attend to victims of sexual violence or unprotected sex whenever MCH/FP facilities are closed.

$\checkmark$ Given the tendency of family planning users to view emergency contraception as an alternative to routine family planning use, training must ensure that emergency contraception is always provided within the context of a broad method mix.

$\checkmark$ As the range of emergency contraception providers expands to enhance physical access to the product, there will be a need to develop new training curricula that reflect the different knowledge levels, time constraints, needs and unique characteristics of each provider group.

\section{TRANSITION TO REGULAR FAMILY PLANNING}

$\checkmark$ While providing emergency contraception services, health care workers must recognize that users as well as non-users of regular family planning may require counseling and support to ensure that emergency contraception is not seen as a "quick-fix" or that it becomes adopted at the expense of more reliable methods.

$\checkmark$ Given the importance of condom-use for prevention of reproductive tract infections, including HIV/AIDS, it is critical that health care providers do not allow the apparent dissatisfaction with less effective methods to discourage condom use among former users of emergency contraception. Current efforts to promote dual protection should be reinforced.

$\checkmark$ While efforts should be made to facilitate the transition from emergency to regular contraceptive use, service delivery protocols for emergency contraception should also respond to the needs of non-users of regular family planning methods or by women who chose to adopt emergency contraception as their "regular" family planning method. 


\section{DISSEMINATION WORKSHOP}

On March 10, 1995 a national workshop was held to disseminate the findings of Phase One of the present operations research study. Sponsored by the World Health Organization, the workshop was attended by more than 80 participants representing the service delivery, academic, and NGO/international donor communities. Each of the districts involved in the study sent delegations, as did the Reproductive Health Research Unit of Baragwanath Hospital (South Africa), where service delivery research on emergency contraception is also currently underway.

In addition to disseminating the results and findings of the operations research study, the workshop had the following three objectives:

- To exchange ideas on emergency contraception based on experiences gathered in Zambia and other African countries.

- To identify the kinds of information still needed in order to develop an introductory strategy for the emergency contraceptive pill in Zambia.

- To identify problems or operational issues associated with the delivery of emergency contraception services that can be resolved through operations research.

Following welcoming remarks by Mrs. J. Nyirenda, Reproductive Health Specialist at the Central Board of Health, the workshop began with a general description of the key events leading to the implementation of the present study: the recommendations of the 1995 Contraceptive Needs Assessment, the procurement by DFID (then ODA) of emergency contraception commodities, and the publication of national family planning/reproductive health guidelines. Following this introduction, a brief technical overview was given on emergency contraception itself, including its history, the various forms it could take, and its mode of operation.

With this beginning, the discussion then shifted to an emphasis on the contents of the present operations research study. The objectives and design of the study were summarized, as were the data collection instruments used and the research findings to date. As in the previous chapters of this report, the presentation of findings was structured in terms of the five broad emergency contraception themes (accessibility, administration, management of side effects, training, and transition to regular family planning use), with an emphasis on the implications of the findings for future research or programmatic action.

One of the truly distinctive features of this study is the fact that it has been, ever since its inception, a highly participatory exercise. Indeed, most of the project's service delivery, training and even data collection components are managed by a steering committee whose membership is drawn from providers at each of the service delivery points involved in the project. To ensure the committee's continued input into this event, an open panel discussion was scheduled to solicit the views and opinions of its members.

The goal of the panel discussion was to offer a forum for the providers to reflect upon the findings outlined during the previous session and, even more importantly, to evaluate critically the programmatic implications of these findings for their own work. During the often heated 
discussion, providers addressed such issues as expanding the range and number of outlets providing emergency contraception services; the importance of in-house training on emergency contraception for all clinic staff; the advantages and potential risks of distributing PC-4 prophylactically; and the need for greater dissemination of information on emergency contraception to the community at large. In many cases, provider comments served as catalysts for more open discussion among the workshop participants. In other cases, participants simply wanted to hear what the providers had to say about PC-4: their clinical experience with it, their personal and ethical views of it; and the practical difficulties they encountered in providing it on a day to day basis.

Using many of the points raised during the previous presentations, the morning session was brought to a close with a brief review of other regional activities being undertaken in emergency contraception, particularly those being implemented by the International Consortium on Emergency Contraception., a joint research effort sponsored by the Concept Foundation, the International Planned Parenthood Federation (IPPF), the Pacific Institute for Women's Health, Pathfinder International, the Population Council, the Program for Appropriate Technology in Health (PATH) and the World Health Organization (WHO).

While the focus of the morning session was on the presentation and discussion of research results, the afternoon's activities centered on the final two objectives of the workshop: 1) to identify information still needed to formulate a national introductory strategy for emergency contraception; and 2) to identify problems or operational issues that could be resolved through operations research. To help orient participants in addressing these objectives, the first presentation of the afternoon explored the concept of contraceptive introduction and outlined in some detail the processes typically involved in the development of any introductory strategy. These processes included such elements as the assessment of user needs and service capabilities; the selection of a product; the development of a distribution plan; the training of providers; the dissemination of information; and the monitoring and evaluation of services. Throughout the discussion, participants were asked to reflect upon the results presented earlier in the day to determine whether, in their own view, the current data on emergency contraception in Zambia were adequate to address each of these components.

Equipped with this broad framework for addressing the elements of a national introductory strategy, workshop participants were then divided into five working groups, each of which was asked to address a number of key issues that had arisen during the day's discussions. The issues included the following:

1. What is the potential role of community-based organizations in providing information and services on emergency contraception to their target populations? What provisions would be required in terms of information dissemination, service delivery, referral systems?

2. What are the moral/ethical issues associated with emergency contraception that affect provision and utilization of services? What information and/or skills can be offered to providers and clients to assist them in making informed decisions?

3. How can youth be provided with quality emergency contraception services, including linkages with family planning, yet maintain confidentiality, privacy, and ease of access? What are the pros and cons of different distribution channels?

4. In efforts to expand the range of personnel authorized to provide emergency contraception, what can various categories of providers (pharmacists, peer counselors, etc.) be expected to do and what would be the minimum level of training required? 
5. What are the factors that affect accessibility to emergency contraception services and information in rural areas? What might be done to overcome these barriers? What would be the pros and cons of the different strategies?

At the conclusion of the group work, participants reassembled to report back and reflect upon their discussions. Given the breadth of topics and the number of participants involved, it is beyond the scope of this document to report in detail the conclusions of each working group. Indeed, many of the comments were largely technical in nature and related to specific questions raised earlier in the day by the workshop's presenters. At a general level, however, the plenary session did highlight a number of core issues or concerns that had come to the surface throughout the day.

Undoubtedly, the issue on most participant's minds was the need to expand delivery of emergency contraception services. As this study clearly showed, family planning clinics are reaching only a portion of those who could potentially benefit from emergency contraception services. Participants agreed that future operations research activities should explore new opportunities to expand the range of emergency contraception providers to include pharmacists, peer counselors, and other community-based health care providers. But apart from distributing emergency contraception pills, many in the workshop felt that even nonhealth related organizations could play an important role in communicating appropriate, culturally relevant information about emergency contraception. Community-based organizations, for example, could serve as catalysts for referring women in emergency situations (particularly victims of rape or other sexual violence) to the appropriate agencies for help. There was even discussion as to how these organizations might work together with police, community leaders (including chiefs in rural areas) and other local authorities to sensitize them to the needs and concerns of such victims.

Related to the issue of expanding emergency contraception services, were the particular problems and concerns facing youth. While there was general agreement that reaching youth would entail entirely new service delivery outlets or sources, participants were reminded that it is all too easy to group youth together as one, and assume they all have the same needs and concerns. For many workshop participants, an important distinction needed to be made between in-school youth, the group addressed through this project, and out-of-school youth who are not only more numerous, but also harder to reach, and quite possibly more in need of emergency contraception services. In tackling the problem of youth accessibility, therefore, participants recommended that operations research activities look beyond traditional institutional outlets such as schools or school-based health facilities and focus on alternative institutions such as youth clubs, community organizations, or even sports associations.

Another important set of concerns that arose throughout the day were the ethical issues surrounding emergency contraception -- particularly the implications of a widely held view that it is, to use the words of one participant, "not merely anti-conception, but antipregnancy". While workshop participants were at pains to emphasize the manner of operation of PC-4 - particularly recent findings to suggest that it most likely operates by preventing ovulation, rather than implantation - the fact remains that many community members and indeed providers, because of misunderstandings about the method of action, will continue to object to emergency contraception on moral grounds. Clearly, the dissemination of accurate information stands to play an important role in clarifying exactly what emergency contraception is and how it works. This is important, not just to allay the concerns of those 
who fear it may function as an abortifacient, but also because we know that many women seek emergency contraception long after the window in which it is effective, precisely because they mistakenly believe it actually does provoke abortion.

The last broad issue to be raised concerned the need for enhancing accessibility in rural areas. Interestingly, one consequence of this study's largely urban focus, was the fact that it confronted the issue of accessibility by focusing on the expansion of outlets or sources through which services and information could be delivered, as opposed to a reduction in the time required to reach them. It was not clear, for example, -- at least not in this study -- that having pills on hand at the time of unprotected sex would influence in any way the timeliness with which a women could access emergency contraception. In rural areas, by contrast, accessibility was seen to depend less on the sources of services and information (since those would be limited anyway), than on the time required to reach them (which was ultimately a function of distance from the source). For many participants, therefore, there was great need for operations research studies that could explore the implications of administering emergency contraception prophylactically. Would it, as many providers suggested, encourage discontinuation of regular family planning use? Or would it, particularly among rural, largely illiterate populations, place unrealistic burdens on women to recall the timing or frequency with which it should be taken?

After an extremely full day of discussions and debate, the workshop closed with much optimism about the future for research on emergency contraception in Zambia. It also closed on a highly positive note in that participants formally and overwhelmingly recommended that emergency contraception be included within the Primary Health Care Provider (PHP) training materials currently being developed by Zambia's Central Board of Health. 


\section{REFERENCES}

Gaisie, K., Anne R. Cross and Geoffrey Nsemukila

1993 Zambia Demographic and Health Survey, 1992. University of Zambia, Central Statistical Office (Lusaka, Zambia), and Macro International Inc. (Columbia, Maryland, USA).

Ho, P.C. and Kwan, M.S.

1993 A prospective randomized comparison of levonorgestrel with the Yuzpe regimen in post-coital contraception. Human Reproduction 8: 389-392.

Hatcher, Robert A., James Trussell, Felicia Stewart, Gary K. Stewart, Deborah Kowal, Felicia Guest, Willard Cates Jr. and Michael S. Policar

1994 Contraceptive Technology, $16^{\text {th }}$ Revised Edition. New York: Irvington Publishers, Inc.

Koster, Winifred

1995 Unplanned Pregnancies, Causes and Effects (unpublished draft). Mongu: Dutch Aid Assistance.

Skibiak, John P., Y. Ahmed, D.M. Chikamata and P.E. Hall

1997 Emergency Contraception: Searching For New Solutions. Paper presented at the $125^{\text {th }}$

Annual Meeting and Exhibition of the American Public Health Association.

Indianapolis, November 12, 1997.

Spicehandler, Joanne; Ruth Simmons et al.

1994 Contraception Introduction Reconsidered: A Review and Conceptual Framework. Geneva: World Health Organization, Special Programme of Research, Development and Research Training in Human

Reproduction, WHO/HRP/ITT/94.1

World Health Organization

1995 An Assessment of the Need for Contraceptive Introduction in Zambia. Expanding Family Planning Options, UNDP/UNFPA/WHO/World Bank Special Programme of Research, Development and Research Training in Human Reproduction. Geneva: World Health Organization,

WHO/HRP/ITT/95.4.

Zambia, Republic of

1997 Family Planning in Reproductive Health: Policy Framework, Strategies and Guidelines. Lusaka: Ministry of Health. 